\title{
Behavioral and immunohistochemical characterization of rapid reconditioning following extinction of contextual fear
}

\author{
Amy R. Williams, Earnest S. Kim, and K. Matthew Lattal \\ Department of Behavioral Neuroscience, Oregon Health \& Science University, Portland, Oregon 97239, USA
}

\begin{abstract}
A fundamental property of extinction is that the behavior that is suppressed during extinction can be unmasked through a number of postextinction procedures. Of the commonly studied unmasking procedures (spontaneous recovery, reinstatement, contextual renewal, and rapid reacquisition), rapid reacquisition is the only approach that allows a direct comparison between the impact of a conditioning trial before or after extinction. Thus, it provides an opportunity to evaluate the ways in which extinction changes a subsequent learning experience. In five experiments, we investigate the behavioral and neurobiological mechanisms of postextinction reconditioning. We show that rapid reconditioning of unsignaled contextual fear after extinction in male Long-Evans rats is associative and not affected by the number or duration of extinction sessions that we examined. We then evaluate c-Fos expression and histone acetylation (H4K8) in the hippocampus, amygdala, prefrontal cortex, and bed nucleus of the stria terminalis. We find that in general, initial conditioning has a stronger impact on c-Fos expression and acetylation than does reconditioning after extinction. We discuss implications of these results for theories of extinction and the neurobiology of conditioning and extinction.
\end{abstract}

One of the most theoretically important findings from research on Pavlovian conditioning is that extinction suppresses behavior without necessarily altering the original association. Several pieces of behavioral evidence support this, including findings that after extinction, the behavior will return with time (spontaneous recovery), changes in context (contextual renewal), or reexposure to the unconditioned stimulus (reinstatement). The fourth piece of evidence for extinction as a suppressive process is that behavior is rapidly reestablished after fewer conditioning trials than are needed to establish the initial behavior (Bouton et al. 2012; Goode and Maren 2014). This rapid reconditioning effect is robust but is generally less studied relative to the other unmasking procedures and little is known about the neurobiology of postextinction reconditioning.

Studies of reconditioning after extinction have revealed that the amount of reconditioning can be influenced by the amount of extinction. For example, following relatively brief extinction, reconditioning occurs more quickly compared to initial conditioning, but following extensive extinction, this effect may be eliminated or reconditioning maybe even slower compared to initial conditioning (e.g., Pavlov 1927; Bouton 1986; Bouton and Swartzentruber 1989; Hart et al. 1995; Rescorla 2001; Leung et al. 2007; Williams and Lattal 2019). Although reconditioning has been used as a tool to assess the strength of extinction learning in the face of neurobiological manipulations (Raybuck et al. 2013; Bolkan and Lattal 2014; Hart et al. 2014), the neurobiology of reconditioning itself is understudied compared to other postextinction unmasking phenomena. Reconditioning is a particularly nice experimental approach for comparing initial conditioning with the postextinction expression of behavior because the conditions during initial conditioning and postextinction reconditioning can be closely matched. Thus, the impact of the same

\section{Corresponding author: lattalm@ohsu.edu}

Article is online at http://www.learnmem.org/cgi/doi/10.1101//m.048439.118. number of conditioning trials can be assessed in groups that are receiving those trials for the first time or for the second time (after extinction).

There is some reason to think that the circuits and molecular mechanisms that underlie initial conditioning and postextinction reconditioning, in general, may differ (e.g., Motanis and Maroun 2012; Perry and McNally 2012). Recent work on fear conditioning and extinction has focused on the extended amygdala, hippocampus, and prefrontal cortex. There are many demonstrations that mechanisms of learning in these regions may be different as a function of behavioral history prior to an associative learning experience. For example, preexposure to a context can change the hippocampal and amygdala requirements of contextual fear conditioning (e.g., Huff et al. 2005). A second fear conditioning session recruits different mechanisms from a first conditioning trial (e.g., Kim and Davis 1993; Maren et al. 1996; Anglada-Figueroa and Quirk 2005) and postextinction reconditioning involves overlapping and distinct molecular mechanisms in the amygdala compared to initial acquisition (Laurent and Westbrook 2009; Motanis and Maroun 2012). The role of the subregions of the medial prefrontal cortex (mPFC) has been mixed, with demonstrations that tetanic stimulation of the mPFC (Deschaux et al. 2011; Zheng et al. 2013) or inactivation of the prelimbic cortex (PL) impairs or enhances postextinction reconditioning in different tasks (Willcocks and McNally 2013; Fu et al. 2016) and other preparations similarly showed mixed effects of PL and infralimbic cortex (IL) inactivation on reacquisition. Finally, many studies have found that the anterior BNST (Alheid and Heimer 1988), a member of the extended amygdala that shares similar connections and

(C) 2019 Williams et al. This article is distributed exclusively by Cold Spring Harbor Laboratory Press for the first 12 months after the full-issue publication date (see http://learnmem.cshlp.org/site/misc/terms.xhtml). After 12 months, it is available under a Creative Commons License (Attribution-NonCommercial 4.0 International), as described at http://creativecommons.org/licenses/by-nc/ $4.0 \%$. 
neuroanatomical makeup with the CeA (Alheid et al. 1995) plays a selective role in aspects of fear conditioning (Lee and Davis 1997; Walker and Davis 1997; Schulz and Canbeyli 1999; Sullivan et al. 2004; Waddell et al. 2006; Davis et al. 2010; Zimmerman and Maren 2011) and reinstatement (Erb and Stewart 1999; Waddell et al. 2006; Goode et al. 2015), but less is known about its role in rapid reacquisition after extinction.

The goal of the following experiments was to characterize the effects of several behavioral variables that may influence postextinction reconditioning of contextual fear (number and duration of extinction sessions, nonreinforced exposure to the context, a history of unconditioned stimulus (US) presentations, and sensitization in reconditioning) and to begin to characterize the brain regions involved by evaluating the effects of initial conditioning and postextinction reconditioning on histone acetylation and the expression of the immediate-early gene c-Fos, two markers of activity that have been shown to be involved in initial conditioning and extinction.

\section{Results}

\section{Experiment 1: reconditioning after 2 or 12 extinction sessions}

Because studies have found both rapid (Napier et al. 1992; Leung et al. 2007) and slow (Bouton 1986; Bouton et al. 2004; Leung et al. 2007) reacquisition following extinction, we evaluated the effects of different amounts of extinction on rapid reconditioning in Experiment 1. Two groups received unsignaled contextual fear conditioning followed by either moderate ( 2 sessions; Group REC 2 EXT) or extensive (12 sessions; Group REC 12 EXT) extinction. Those two groups and the third group with no history in the context (Group COND) then received a single weak conditioning session, followed by tests 1 and $4 \mathrm{~d}$ later.

\section{Initial conditioning and extinction}

An overview of the design of Experiment 1 is shown in Figure 1A. Freezing increased over the two acquisition sessions with no group differences $\left(F_{(1,7)}=26.7, P<0.01\right.$; data not shown; session one: $M=41.03, \mathrm{SEM}=5.76$, session two: $M=71.07, \mathrm{SEM}=7.56$ ). There were no reliable main effects of or interactions with subsequent treatments during extinction or reconditioning in this or any subsequent experiment. Figure $1 \mathrm{~B}$ shows the extinction curves for Groups REC 12 EXT and REC 2 EXT in 6-min time blocks for each session. Separate repeated-measures ANOVAs with session and time block as factors found reliable main effects of extinction session $\left(P^{\prime} \mathrm{s}<0.002\right)$, time block $\left(P^{\prime} \mathrm{s}<0.001\right)$, and a reliable interaction $\left(P^{\prime} \mathrm{s}<0.05\right)$ in both groups. During the final half of the last extinction session, groups showed equivalently low levels of freezing (Extinction Session 12/2 in Fig. 1B), which showed that the two groups reached a common level of performance prior to reconditioning. All groups increased freezing after the shock in the reconditioning session (reliable main effect of Time $\left[F_{(1,21)}=\right.$ 35.67, $P<0.001$; preshock: $M=1.04, \mathrm{SEM}=1.04$, postshock: $M=$ 42.71, SEM = 7.13]).

\section{Postreconditioning tests}

All three groups were exposed to the context with no shock over two test sessions (Fig. 1C). Over the course of testing, the reconditioning groups did not differ as a function of the number of extinction sessions and showed more freezing early in the test sessions compared to the conditioning group. A 2 (Test Session) $\times 4$ (Session Time Block) $\times 3$ (Group) ANOVA revealed a reliable main effect of test session $\left(F_{(1,21)}=33.25, P<0.001\right)$ and Time Block $\left(F_{(3,63)}=49.86, P<0.001\right)$, as well as reliable interactions between Time Block and Group $\left(F_{(6,63)}=3.66, P=0.004\right)$ and Test and Time Block $\left(F_{(3,63)}=4.67, P<0.01\right)$. The interactions with Time Block were driven by different effects in the early blocks compared to the later blocks when freezing was lowest. Further analyses of the first 6 min of testing revealed that across the two tests, the two reconditioning groups did not differ from each other $\left(P^{\prime} \mathrm{s}>0.40\right)$, but each reconditioning group differed from Group COND during one of the tests (Test 1: Group REC 12 EXT vs. COND, $q=2.54, P=$ 0.048; Test 2: Group REC 2 EXT vs. COND, $q=2.74, P=0.031$ ). When combined, the two reconditioning groups differed from the conditioning group over both tests $\left(t_{(22)}=2.949, P=0.007\right)$. These results suggest that reconditioning after extinction is rapid and does not differ as a function of the number of extinction sessions.

\section{Experiment 2: Effects of a postextinction US in a different context}

The first experiment found that a single context-footshock pairing after extinction caused freezing to be reestablished in the context. It is conceivable that the quick reemergence of conditioned freezing following a postextinction context-shock pairing could be due to reinstatement to the US alone (Rescorla and Heth 1975) or a generalized sensitization of freezing due to a history of repeated shock (e.g., Rau and Fanselow 2009). The next two experiments 
examined these possibilities. In Experiment 2, two groups of rats were conditioned in Context $\mathrm{A}$ and received 3 (Group REC 3 EXT) or 6 (Group REC 6 EXT) extinction sessions in Context A, followed by a brief reconditioning session in Context A. A separate group received conditioning in Context A followed by 3 sessions of extinction in Context $\mathrm{A}$, then received brief conditioning in Context B (Group SWITCH 3 EXT). This group served as a control for the nonassociative impact of the postextinction shock on test freezing. A fourth group received no initial conditioning or extinction and only received the single shock in Context A (Group COND). All groups were tested in Context A the day after reconditioning, followed by a second test in Context B the next day, then a final test back in Context $\mathrm{A}$.

\section{Conditioning, extinction, and reconditioning}

An overview of the design of Experiment 2 is shown in Figure $2 \mathrm{~A}$. All three reconditioning groups increased freezing from Acquisition Session $1(M=46.63, \mathrm{SEM}=2.45)$ to Session $2(M=66.78$, $\mathrm{SEM}=3.83$; main effect of acquisition session $\left(F_{(1,14)}=35.3, P>\right.$ $0.001)$ ). As can be seen in Figure $2 \mathrm{~B}$, all extinction groups showed a decrease in freezing over the course of extinction. A two-way RMANOVA comparing REC 3 EXT and SWITCH 3 EXT across extinction showed a significant effect of Extinction session $\left(F_{(2,28)}=\right.$ 53.42, $P<0.001)$, and a separate one-way ANOVA found a reliable main effect of extinction session in $\operatorname{REC} 6 \operatorname{EXT}\left(F_{(5,35)}=38.12, P<\right.$ $0.001)$. There were no differences in freezing among groups during the reconditioning session (data not shown). A RMANOVA comparing the average freezing 30 sec pre- and postshock (Time) across all groups in the reconditioning session found a significant main effect of Time $\left(F_{(3,28)}=36.05, P<0.001\right.$; preshock: $M=0.00$,
SEM $=0.00$; postshock: $M=33.59$, SEM $=5.45)$, but not Group $\left(F_{(3,28)}=0.487, P=0.694\right)$ or Time $\times$ Group interaction $\left(F_{(3,28)}=\right.$ $0.487, P=0.694)$.

\section{Postreconditioning tests}

Test 1: postreconditioning test in Context A. Twenty-four hours following weak reconditioning, all four groups were exposed to the original context (Context A) for $24 \mathrm{~min}$ (Fig. 2C). All groups that received the single footshock in Context A showed moderate to high levels of freezing at the beginning of Test 1 , whereas Group SWITCH 3 EXT, which was shocked in Context B, showed no freezing in Context A. A Group $\times$ Test Block ANOVA revealed reliable main effects of Group and Test Block $\left(F^{\prime} \mathrm{s}>10.9, P^{\prime} \mathrm{s}<0.001\right)$, as well as a reliable interaction $\left(F_{(9,84)}=4.40, P<0.001\right)$. The two reconditioning groups did not differ from each other $(P=0.331)$ and both differed from Group SWITCH 3 EXT $\left(P^{\prime} \mathrm{s}<0.005\right)$. Group REC 6 EXT differed from the Group COND $(P=0.021)$, but Group REC 3 EXT was not reliably different from Group COND.

Test 2: postreconditioning test in Context $B$. When tested in Context B, only Group SWITCH 3 EXT showed robust freezing (Fig. 2C, Context B), which was the context in which they were previously shocked. A Group $\times$ Test Block ANOVA revealed reliable main effects of Test Block and Group $\left(F_{(3,84)}=16.85\right.$ and $F_{(3,28)}=$ 8.269 , respectively, $\left.P^{\prime} \mathrm{s}<0.001\right)$, as well as a reliable interaction $\left(F_{(9,84)}=10.03, \quad P<0.001\right)$. Follow-up Tukey tests found that Group SWITCH 3 EXT differed from each of the other three groups over the session $\left(P^{\prime} \mathrm{s}<0.005\right)$. This result showed that acquisition and rapid reacquisition did not generalize across contexts, as Groups COND, REC 3 EXT, and REC 6 EXT showed little freezing in a different context.

Test 3: second test in Context $A$. The final test consisted of a reexposure to Context A (Fig. 2C). A Group $\times$ Test Block ANOVA revealed reliable main effects of Test Block and Group $\left(F_{(1,27)}=33.339\right.$ and $\left.F_{(3,27)}=4.123, P^{\prime} \mathrm{s}<0.02\right)$, as well as a reliable interaction $\left(F_{(3,27)}=6.335, \quad P=\right.$ 0.002). Follow-up Tukey's HSD tests found that both reconditioning groups differed from the conditioning group during the first 6 min of Test 3 (REC 6 EXT vs. COND, $P=0.004$; REC 3 EXT vs. COND, $P=0.04)$. It is notable that Group COND did not freeze during this test, suggesting that extinction in the first two tests eliminated freezing in the COND group, but not in the REC groups.

These findings show that the reconditioning effect is specific to the context in which reconditioning occurs. The absence of freezing in Context $\mathrm{A}$ in the SWITCH 3 EXT group shows that the freezing observed in the reconditioning groups is not due simply to generalization or sensitization. This experiment also replicated the rapid reconditioning effect observed in Experiment 1, but, in Test 1, this effect only occurred in the reconditioning group that received more extinction; no difference was observed between the moderate extinction group and the conditioning group. However, the freezing that was established in Group COND rapidly extinguished and did not persist to a second test in Context $\mathrm{A}$, whereas the
Figure 2. Rapid reacquisition of contextual fear occurs after 3 or 6 sessions of extinction and is specific to the context of reconditioning. $(A)$ Overview of the design of Experiment 2. The times listed represent the total time of exposure to the context for a given session. A " + " sign indicates a single $0.75 \mathrm{~mA}$ shock and $a$ " -" sign indicates the exposure to the context without shock. The treatment context is represented by $A$ or $B$. (B) Mean freezing during each extinction session (E1-6 or E1-3) in rats that received fear conditioning Days 1 and 2 (REC 6 EXT) or Days 4 and 5 (REC 3 EXT and REC 3 SWITCH). (C) Mean freezing during the three tests for each group. Tick marks on the $X$-axis reflect 6-min time blocks. $\left(^{*}\right)$ REC groups vs. SWITCH, $P<0.005$, REC 6 EXT vs. COND, $P<0.05$; (\#) SWITCH vs. all other groups, $P<$ $0.005 ;\left({ }^{\wedge}\right)$ REC groups vs. COND, $P^{\prime} s<0.05$. Error bars represent the standard error of the mean. 
freezing in both reconditioning groups did. Thus, reconditioning effects may be manifest early or late in testing.

\section{Experiment 3: reconditioning with matched US and context exposure}

In Experiment 3, we again evaluated the effects of exposure to shock on nonassociative performance, as well as the potential contribution of differences in context exposure as a contributor to the differences between conditioning and reconditioning groups. In Experiments 1 and 2, the reconditioning groups received more total context exposure than did the conditioning group. This is a potential confound that could weaken reconditioning (through latent inhibition effects; e.g., Mowrer 1987) or strengthen reconditioning (through perceptual learning and/ or conjunctive representational effects; e.g., Rudy and O'Reilly 1999). In this experiment, four groups received conditioning with a single shock in Context A. For Group REC SAME, this occurred after initial conditioning and extinction in Context A; for Group REC DIFF, this occurred after an initial conditioning and extinction in Context B; for Group COND SAME, this occurred after equivalent nonreinforced exposure to Context A; for Group COND DIFF, this occurred after an identical amount of nonreinforced exposure to Context B. Thus, Group REC SAME received the single shock after conditioning and extinction, as in Experiments 1 and 2. Group REC DIFF served as a control to match the history of shock exposure and nonreinforced context exposure. Group COND SAME served as a control that received identical context exposure to address potential latent inhibition or perceptual learning. Group COND DIFF was the same group used in Experiments 1 and 2, but it received nonreinforced exposure to Context $\mathrm{B}$ to match handling and context exposure to Group COND SAME.

\section{Results}

\section{Conditioning, extinction, and reconditioning}

An overview of the design of Experiment 3 is shown in Figure 3A. Shocked groups increased freezing from Acquisition Session 1 $(M=50.74$, SEM = 3.63) to Session $2(M=78.91$, SEM = 3.15), whereas No Shock groups did not freeze $(M<1.0 \%$ in each session); main effects of Session $\left(F_{(1,30)}=98.04, P<0.001\right)$, Shock Group $\left(F_{(1,30)}=\right.$ 434.2, $P<0.001)$ and a reliable interaction $\left(F_{(1,30)}=102.03, P<\right.$ 0.001 ). As can be seen in Figure $3 \mathrm{~B}$, the shocked groups showed a decrease in freezing over the course of extinction, while the nonshocked groups continued to maintain low levels of freezing. An ANOVA found reliable main effects of extinction session, time block, and group (all $P^{\prime} \mathrm{s}<0.001$ ).

\section{Test}

Figure $3 \mathrm{C}$ shows freezing during the 24-min test in Context A. Both reconditioning groups showed higher levels of freezing compared to the conditioning groups and the two reconditioning groups differed from each other. A 2 (Context of postextinction shock: Same or Different) $\times 2$ (Conditioning: Initial Conditioning or Reconditioning) $\times 4$ (Test Block) ANOVA revealed reliable main ef- fects of Test Block $\left(F_{(3,84)}=14.30, P<0.001\right)$, Conditioning $\left(F_{(1,28)}=\right.$ 16.63, $P<0.001)$, and Context $\left(F_{(1,28)}=5.00, P=0.033\right)$, as well as reliable interactions between Time Block and Conditioning $\left(F_{(3,84)}=8.36, P<0.001\right)$ and Conditioning and Context $\left(F_{(1,28)}=\right.$ 7.03, $P=0.013)$. Further analysis of the interactions found more test freezing in Group REC SAME compared to Group REC DIFF $(P=0.02)$ and that both reconditioning groups differed from both conditioning groups $\left(P^{\prime} \mathrm{s}<0.005\right)$, which did not differ from each other. These findings confirm the findings from Experiment 2 that reconditioning effects are not due entirely to nonassociative contributions of the postextinction shock. However, a history of conditioning did result in the single footshock having a much larger impact compared to groups that did not have that history, consistent with findings in the stress-enhanced fear learning literature (SEFL) (Rau et al. 2005). Finally, this experiment found no evidence that context preexposure promoted conditioning with the single footshock and appeared to weaken responding in a context-independent manner, possibly suggesting that extensive handling and context exposure weakens the impact of a single shock.

\section{Experiment 4: reconditioning after short or long extinction sessions}

The first three experiments found rapid reacquisition after extinction. This effect was not always robust (e.g., Group REC 3 EXT in Experiment 2), but there was no evidence that postextinction reconditioning was impaired relative to initial conditioning. There are many demonstrations that massive extinction may slow reacquisition (Bouton 1986; Leung et al. 2007) and we have previously found that massive extinction impairs rapid reacquisition of contextual fear in mice (Williams and Lattal 2019). It is notable that in Experiments 1-3 freezing extinguished quickly and showed little spontaneous recovery across extinction sessions. Some work has shown that preventing conditioned responding during extinction can impair extinction learning (Krupa and Thompson 2003; 
Sierra-Mercado et al. 2006) and the absence of spontaneous recovery may create a less persistent extinction effect (Leung and Westbrook 2008). Further, a lack of conditioned responding in later extinction sessions could be preventing prediction error mechanisms that allow for extinction (Rescorla 2000) or gradual extinction that could cause stronger inhibition of conditioned responding (Gershman et al. 2013). All of this would suggest that our extinction procedures with large numbers of extinction sessions (6 or 12) did not have much additional impact once responding had ceased. Thus, in Experiment 4 we examined if more gradual suppression of conditioned freezing over multiple extinction sessions could deepen inhibitory learning and impair rapid reacquisition.

\section{Results}

\section{Conditioning, extinction, and reconditioning}

The design of Experiment 4 is summarized in Figure 4A. All groups increased freezing across the two acquisition sessions $\left(F_{(1,20)}=\right.$ $36.149, P<0.001$; session one: $M=39.97$, $\mathrm{SEM}=4.24$; session two: $M=65.21$, SEM $=4.32$ ). Figure $4 \mathrm{~B}$ shows extinction in 3-min time blocks. Extinction caused conditioned freezing to lower in both groups. To compare the two extinction durations during the course of extinction, we compared groups during the first 6 min of each session. A RMANOVA found a significant main effect of Group $\left(F_{(1,20)}=4.89, P<0.05\right)$ and Extinction session $\left(F_{(3,60)}=\right.$ 104.67, $P<0.001)$, as well as a significant interaction $\left(F_{(3,60)}=\right.$ $3.95, P=0.012)$. Further analysis of the interaction found no group differences in the first 6 min of Extinction Sessions 1 or $4\left(P^{\prime} \mathrm{s}>\right.$ 0.21 ), but there were differences in Extinction Sessions 2 and 3 $\left(P^{\prime} \mathrm{s}<0.05\right)$. It is worth noting that one animal in the 6-min group stayed at $100 \%$ freezing during the course of extinction and testing, which kept the group means above zero during the final extinction block. Median percent freezing during the final 3-min of the last extinction session was 0.0 in both groups. Thus, the two groups began and ended extinction with similar levels of freezing,
A

\begin{tabular}{|c|c|c|c|c|}
\hline Experiment 4 & $\begin{array}{c}\text { Acquisition } \\
\text { Days 1-2 }\end{array}$ & $\begin{array}{c}\text { Extinction } \\
\text { Days 3-6 }\end{array}$ & $\begin{array}{c}\text { Recond } \\
\text { Day 7 }\end{array}$ & $\begin{array}{c}\text { Test } \\
\text { Day 8 }\end{array}$ \\
\hline 6 MIN & $\mathrm{A}++++$ & 6 MIN A - & $\mathrm{A}+$ & \multirow{2}{*}{$\mathrm{A}-$} \\
\hline $\mathbf{2 4}$ MIN & $\mathrm{A}++++$ & $24 \mathrm{MIN} \mathrm{A} \mathrm{-}$ & $\mathrm{A}+$ & \\
\hline
\end{tabular}

B

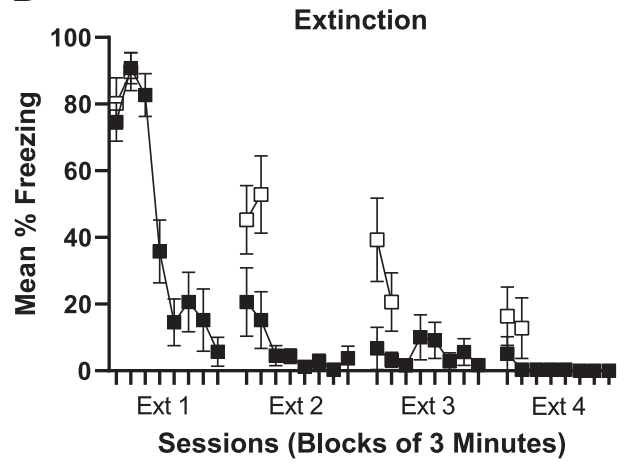

C

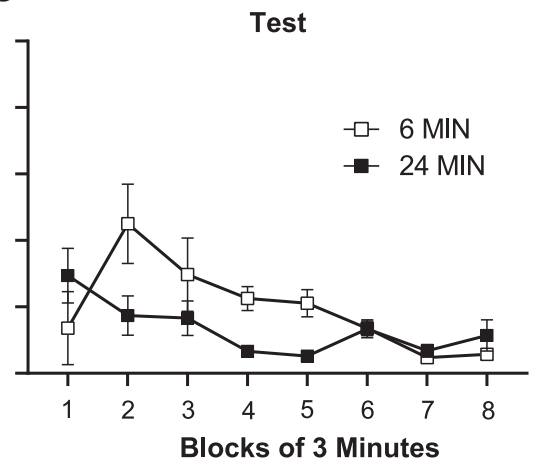

Figure 4. Reacquisition does not differ as a function of the extinction session duration. (A) Overview of the design of Experiment 4. The times listed represent the total time of exposure to the context for a given session. A " + " sign indicates a single $0.75 \mathrm{~mA}$ shock and a " - " sign indicates the exposure to the context without shock. (B) Mean freezing during each extinction session. (C) Mean freezing during the test for each group. Tick marks on the $X$-axis reflect 3-min time blocks. Error bars represent standard error of the mean. meaning that both groups started reconditioning from a common low level of performance.

During reconditioning, groups did not show within-session differences in freezing (data not shown). A RMANOVA comparing the freezing 30 sec pre- and postshock found a significant effect of Time $\left(F_{(1,20)}=12.36, P<0.005\right.$; preshock: $M=6.81, \mathrm{SEM}=4.70$, postshock: $M=32.95, \mathrm{SEM}=8.61)$, but not a significant main effect of Group $\left(F_{(1,20)}=0.74, P=0.400\right)$ or a Time $\times$ Group Interaction $\left(F_{(1,20)}=0.023, P=0.880\right)$.

\section{Test 1: postreconditioning test}

Figure 4C shows freezing during the postreconditioning test. A RMANOVA found no reliable main effect of Group $\left(F_{(1,20)}=1.47\right.$ $P=0.239$ ), but did find a reliable main effect of Time Block $\left(F_{(7,140)}=6.682, P<0.001\right)$ and a reliable Time Block $\times$ Group interaction $\left(F_{(7,140)}=2.110, P=0.046\right)$. The most liberal simple effects analysis revealed a group difference only on Block $2\left(t_{(20)}=2.36\right.$, $P=0.028$ ). This finding suggests that, as with the number of extinction sessions, duration of extinction session has little impact on the amount of reconditioning.

\section{Experiment 5: immunohistochemical characterization of rapid reconditioning}

These first four experiments demonstrated that postextinction reconditioning is associative, rapid, and robust against different extinction treatments; it occurs at similar levels when different number or durations of extinction sessions are used. To begin to explore the brain mechanisms underlying reconditioning, we conducted an immunohistochemical experiment to examine different brain regions that may be engaged by postextinction reconditioning. We focused on histone acetylation and c-Fos expression in the mPFC, amygdala, hippocampus, and BNST, regions that have been shown to be involved in fear conditioning and extinction. By using the same conditioning procedure (a single contextshock pairing) at the same time for each group, this experiment allowed for the direct comparison of acquisition and reacquisition on the brain regions important for fear learning. Three groups received a single context-shock pairing prior to sacrifice. For Group COND, this was their first conditioning episode (initial conditioning); for Groups REC-EXT and REC-NO EXT, this was their second conditioning episode (reconditioning). Group REC-EXT received extinction between conditioning and reconditioning; Group REC-NO EXT did not receive extinction prior to reconditioning. Group HAND was only handled. These groups allowed us to compare initial conditioning with postextinction reconditioning, and the inclusion of REC-NO EXT allowed us to evaluate the effects of the second conditioning episode independent of extinction.

\section{Conditioning, extinction, and reconditioning}

The design of Experiment 5 is summarized in Figure 5A. Over two contextual fear conditioning sessions, both REC-EXT and REC-NO EXT acquired conditioned freezing to the context. A twoway RMANOVA comparing Group $\times$ Acquisition Session showed a significant within-subjects effect of Acquisition 
A

\begin{tabular}{|c|c|c|c|c|}
\hline Experiment 5 & $\begin{array}{c}\text { Acquisition } \\
\text { Days 1-2 }\end{array}$ & $\begin{array}{l}\text { Extinction } \\
\text { Days 3-5 }\end{array}$ & $\begin{array}{l}\text { Recond/ } \\
\text { Cond } \\
\text { Day } 6\end{array}$ & $\begin{array}{c}\text { Euthanasia } \\
\text { Day } 6\end{array}$ \\
\hline REC-EXT & $12 \min$ & $24 \min -$ & \multirow{3}{*}{$3 \min +$} & \multirow{4}{*}{$\begin{array}{l}\text { 50-90 min } \\
\text { later }\end{array}$} \\
\hline REC-NO EXT & ++++ & Handled & & \\
\hline COND & \multicolumn{2}{|c|}{ Handled } & & \\
\hline HAND & \multicolumn{2}{|c|}{ Handled } & Handled & \\
\hline
\end{tabular}

B

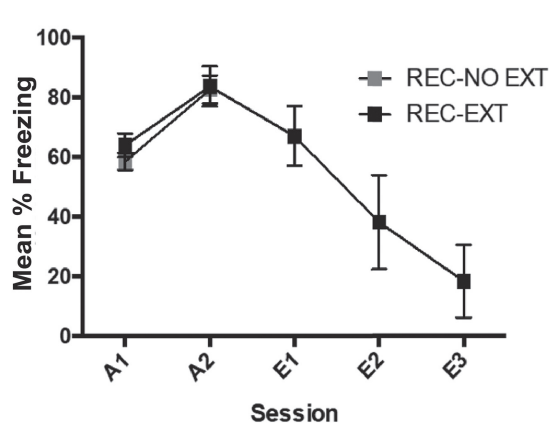

C

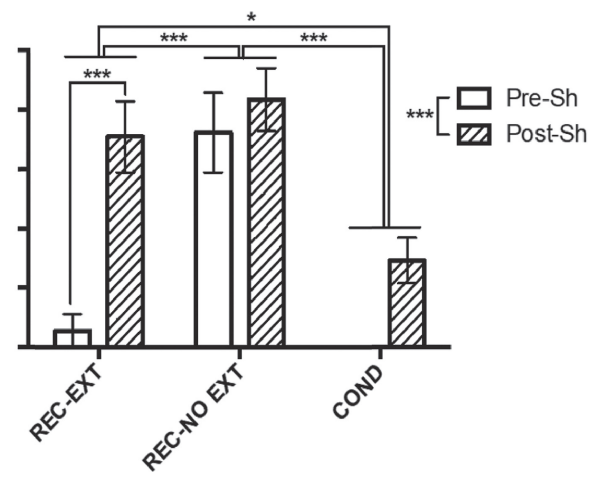

Figure 5. Extinction and rapid reacquisition prior to immunohistochemistry. (A) Overview of the design of Experiment 4. The times listed represent the total time of exposure to the context for a given session. A " + " sign indicates a single $0.75 \mathrm{~mA}$ shock and a " - " sign indicates the exposure to the context without shock. (B) The acquisition and extinction curves from Groups REC-EXT and REC-NO EXT as shown by the mean percent freezing for each session; $A=$ acquisition session, $E=$ extinction session (C) Mean percent freezing in the $30 \mathrm{sec}$ pre- and postshock on Day 6 during reconditioning. Rapid reacquisition of freezing relative to initial acquisition occurred in both REC groups, but only in REC-EXT relative to preshock freezing. Significance between groups is represented by $\left.{ }^{\star \star *}\right) P<0.001$; (*) $P<0.05$. REC-EXT, $n=6$; REC-NO EXT, $n=6$; COND, $n=6$; HAND, $n=6$. Error bars represent standard error of the mean.

Session $\left(F_{(1,10)}=36.86, P<0.001\right.$; session one: $M=61.24$, SEM = 2.44 , session two: $M=83.20, \mathrm{SEM}=3.92)$, but not a main effect of Group $\left(F_{(1,10)}=0.32, P=0.583\right.$; REC-EXT: $M=73.83, \operatorname{SEM}=4.76$, REC-NO EXT: $M=70.61, \operatorname{SEM}=4.49)$ or an interaction $\left(F_{(1,10)}=\right.$ $0.386, P=0.548)$. During 3 sessions of extinction, animals in REC-EXT decreased their conditioned freezing response (Fig. 5B). A one-way RMANOVA revealed a significant within-subjects effect of Extinction Session on session average percent freezing $\left(F_{(2,10)}=\right.$ $16.69, P<0.001)$ that was driven by the significantly lower freezing in E3 compared to E1 $\left(q_{(15)}=3.7948, P<.05\right)$. While E3 session average freezing did not show animals extinguishing to $0 \%$ freezing, all animals in REC-EXT were near $0 \%$ freezing in the last $3 \mathrm{~min}$ of E3 $(M=2.89$, SEM $=2.89)$.

During reconditioning, the reconditioning group that had not received extinction (REC-NO EXT) showed high levels of freezing before and after the shock. Groups REC-EXT and COND showed low levels of freezing prior to the shock and increased by different amounts after the shock (Fig. 5C). A RMANOVA comparing percent time spent freezing in the 30 sec before and aftershock by each Group (Time $\times$ Group) found a significant main effect of Group $\left(F_{(2,15)}=23.46, P<0.001\right)$, within-subjects effect of Time $\left(F_{(1,15)}=34.41, P<0.001\right)$, and a trending interaction effect $\left(F_{(2,15)}\right.$ $=3.55, P=0.054)$. The main effect of Time was caused by significantly more freezing shown aftershock relative to before shock and the main effect of Group was driven by significantly more freezing by REC-NO EXT relative to COND $\left(q_{(15)}=7.10, P<0.001\right)$ and REC-EXT $\left(q_{(15)}=4.44, P<0.001\right)$. Additionally, REC-EXT showed significantly more freezing than COND $\left(q_{(15)}=2.65, P<\right.$ $0.05)$, indicating that both reconditioning groups froze more than COND and that a lack of extinction training causes higher freezing in general (REC-NO EXT $>$ REC-EXT). The trending interaction effect showed that only REC-EXT had significantly more freezing postshock relative to preshock $\left(q_{(15)}=6.85, P<\right.$ $0.001)$, while COND $\left(q_{(15)}=1.07, P=\right.$ $0.262)$ or REC-NO EXT did not $\left(q_{(15)}=\right.$ $0.671, P=0.957)$. Animals were euthanized 50-90 min after reconditioning for immunohistochemistry.

\section{c-Fos immunohistochemistry}

All regions and subregions were analyzed for group differences in c-Fos-positive cells. Representative DAB IHC staining for c-Fos for each group in a significant region (DG) can be seen in Figure 6A. The full summary of results is in Table 1.

Only the hippocampus had a significant difference in c-Fos among groups in whole region analyses (Table 1 ). A oneway ANOVA found a significant main effect of Group $\left(F_{(3,19)}=11.1, P<0.001\right)$ that was driven by significantly more c-Fos-positive cells in COND $\left(q_{(19)}=7.95\right.$, $P<0.001)$, REC NO-EXT $\left(q_{(19)}=5.40, P<\right.$ $0.01)$, and REC-EXT $\left(q_{(19)}=4.84, P<.05\right)$ relative to HAND. Subsequent analyses focused on the DG (Table 1; Fig. 7). In a one-way ANOVA comparing c-Fospositive cells in the DG among groups there was a significant main effect of Group $\left(F_{(3,19)}=16.6, \quad P<0.001\right)$, driven by significantly more DG c-Fos expression in REC-EXT $\left(q_{(19)}=4.43, P<0.05\right)$, REC-NO EXT $\left(q_{(19)}=5.68, P<0.01\right)$, and COND $\left(q_{(19)}=9.93, P<\right.$ $0.01)$ relative to HAND and significantly more DG c-Fos expression in COND relative to REC-EXT $\left(q_{(19)}=5.04, P<0.05\right)$ and REC-NO $\operatorname{EXT}\left(q_{(19)}=4.25, P<0.05\right)$. This effect suggests that both acquisition and reacquisition cause increased DG c-Fos expression, but that initial acquisition causes the strongest activation of DG c-Fos expression.

While the aBNST as a whole did not show significant group differences in c-Fos expression, there was a reliable main effect of Group in the adBNST subregion $\left(F_{(3,20)}=6.16, P<0.01\right)$ due to significantly more c-Fos-positive cells in COND relative to HAND $\left(q_{(20)}=5.66, P<0.01\right)$ and REC-EXT $\left(q_{(20)}=4.76, P<0.05\right)$. Similar to the DG, this result implies that initial acquisition causes a stronger activation of c-Fos in the adBNST relative to reacquisition or simple handling.

\section{H4K8ac immunohistochemistry}

All regions and subregions were analyzed for group differences in H4K8ac-positive cells, but only the lateral amygdala subregion showed significant differences. Representative fluorescent IHC staining for H4K8ac for each group in a significant region (LA) can be seen in Figure 6B. A summary of the results of each region is in Table 2. A one-way ANOVA found a significant main effect of Group on cells positive for H4K8ac within the lateral amygdala $\left(F_{(3,18)}=3.64, P<0.05\right)$. The significant Group effect was driven by significantly more $\mathrm{H} 4 \mathrm{~K} 8 \mathrm{ac}-$ positive cells in COND relative to HAND controls $\left(q_{(18)}=4.48, P<0.05\right)$, which suggested that conditioning significantly activated histone acetylation within the lateral portion of the amygdala (Fig. 7D). 
A

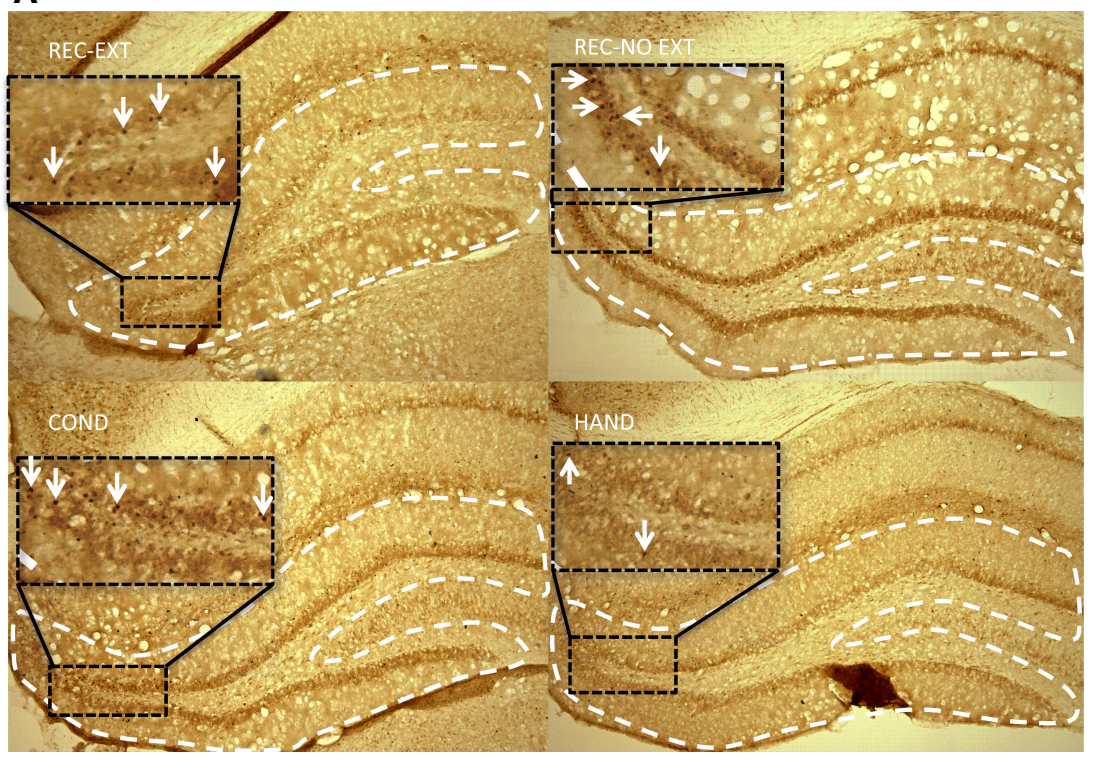

B

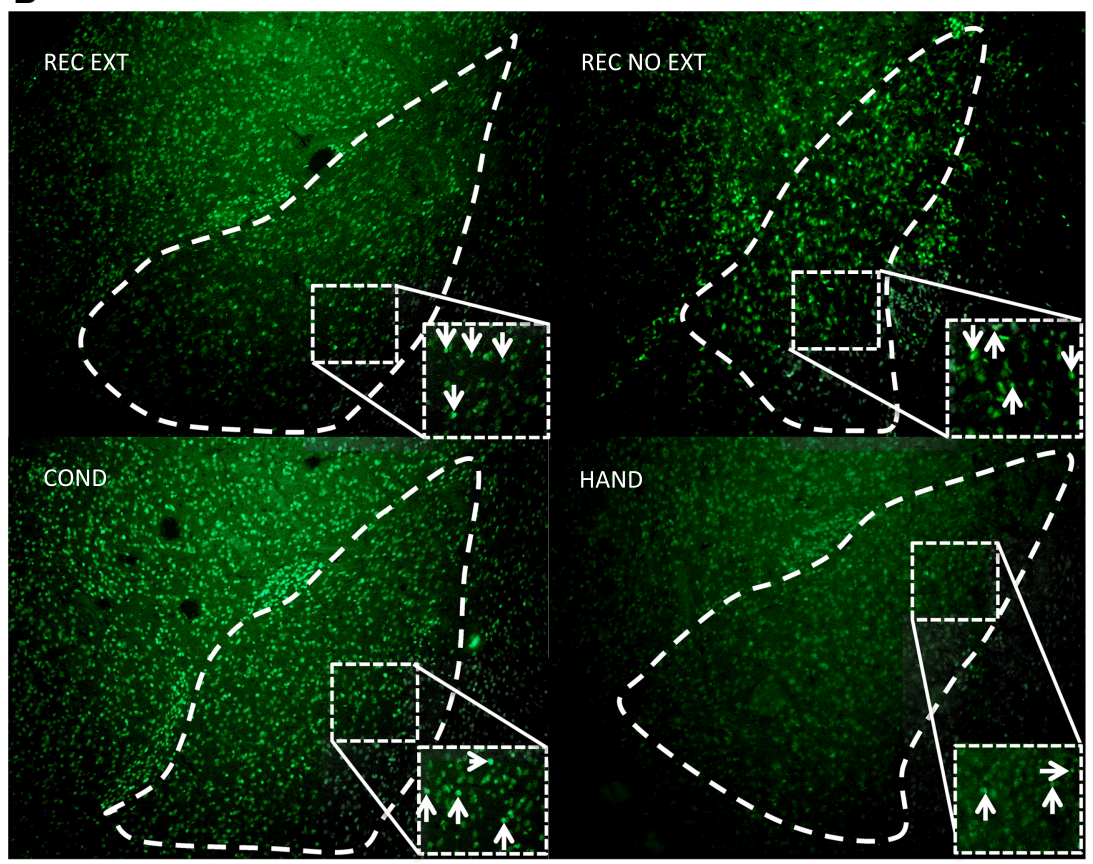

Figure 6. Representative coronal slices of c-Fos and H4K8ac staining. $(A)$ The four panels are representative images of average c-Fos staining in DG for each group that resulted from DAB IHC. The largedashed white line represents what region was counted for the DG. The small-dashed black square shows a magnified region of the slices with white arrows indicating cells showing positive DAB staining (not all stained cells are indicated with an arrow to maintain clarity). ( $B$ ) The four panels are representative images of average H4K8ac staining in LA for each group that resulted from fluorescent IHC. The large-dashed white line represents what region was counted for the LA. The small-dashed white square shows a magnified region of the slices with white arrows indicating cells showing positive fluorescent staining (not all stained cells are indicated with an arrow to maintain clarity).

fect was for the most part independent of the amount of extinction and returned after the postreconditioning behavior had been extinguished during initial tests. Additionally, this work shows that rapid reacquisition of contextual fear is not a result of (1) a generalized enhancement in fear that may occur after reexposure to a shock US in a different context, (2) a generalized increase in responsivity to a single US following extensive conditioning in a different context (although this did cause some generalized increase in freezing), or (3) increased contextual learning relative to conditioning groups following nonreinforced context exposure. Thus, the return of postextinction freezing is a specific context-associated effect of reconditioning. Finally, although reconditioning increased histone acetylation or c-Fos expression relative to handling controls, this effect was not as large as the effect of initial conditioning.

The finding of rapid reacquisition following extinction has been seen many times in the literature (e.g., Napier et al. 1992; Bouton et al. 2004; Leung et al. 2007) and is consistent with other postextinction processes, such as spontaneous recovery, reinstatement, and contextual renewal (Pavlov 1927; Rescorla and Heth 1975; Bouton and Bolles 1979a,b; Robbins 1990; Rescorla 2004). The current findings reinforce reacquisition as yet another way by which to study the way in which fear promoting and inhibitory associative memories interact and compete for expression during and after extinction.

Although some studies have found that extensive extinction weakens postextinction reconditioning, sometimes to the point that reacquisition is slower compared to the initial acquisition, we found that extensive extinction had no effect on reconditioning. This is in contrast to our previous work with mice, which found that extensive extinction eliminated rapid reconditioning (Williams and Lattal 2019). The slow rate of reacquisition that sometimes occurs could be due to a number of factors, including performance variables and differences in exposure to the context causing latent inhibition (Bouton and Swartzentruber 1989; Brooks et al. 2003; Williams and Lattal 2019). We found that extensive context preexposure did appear to weaken initial conditioning, but this was not

\section{General discussion}

These experiments demonstrated that rapid reacquisition of contextual fear occurs following extinction in male Long-Evans rats. Thus, as with other postextinction procedures, rapid reconditioning of contextual fear appears to involve the unmasking of a context-shock association that is suppressed by extinction. This ef- specific to the context of preexposure (Experiment 3). Comparing our results with rats with our previous work in mice is complicated because conditioned freezing in mice is difficult to distinguish from general inactivity. This may mask any subtle reconditioning effects because nonassociative freezing in mice is above zero and extinction does not reach a level of zero percent freezing (Lattal and Maughan 2012; Tipps et al. 2014; Crabbe et al. 2016; Williams 
Table 1. Mean \pm SEM of c-Fos-positive cells in every region selected following Day 6

\begin{tabular}{|c|c|c|c|c|c|}
\hline & REC-EXT & REC-NO EXT & COND & HAND & ANOVA RESULT \\
\hline mPFC & $294.3 \pm 53.3$ & $260.4 \pm 26.9$ & $298.6 \pm 39.8$ & $206.1 \pm 34.5$ & $F_{(3,20)}=1.15, P=0.352$ \\
\hline IL & $124.0 \pm 20.3$ & $117.3 \pm 11.6$ & $131.6 \pm 18.8$ & $82.1 \pm 13.9$ & $F_{(3,20)}=1.75, P=0.188$ \\
\hline PrL & $170.3 \pm 33.8$ & $143.1 \pm 18.3$ & $167.1 \pm 23.7$ & $124.0 \pm 20.8$ & $F_{(3,20)}=0.78, P=0.519$ \\
\hline \multicolumn{6}{|l|}{ Amygdala } \\
\hline LA & $14.6 \pm 3.8$ & $13.9 \pm 2.6$ & $23.4 \pm 3.6$ & $17.3 \pm 3.0$ & $F_{(3,20)}=1.73, P=0.194$ \\
\hline BLA & $32.3 \pm 6.5$ & $23.9 \pm 5.4$ & $35.8 \pm 5.5$ & $41.5 \pm 5.9$ & $F_{(3,20)}=1.60, P=0.220$ \\
\hline $\mathrm{CeA}$ & $6.2 \pm 2.9$ & $7.2 \pm 1.6$ & $12.5 \pm 3.0$ & $5.5 \pm 1.0$ & $F_{(3,20)}=1.94, P=0.155$ \\
\hline dHipp & $22.0 \pm 2.8^{\mathrm{a}}(n=5)$ & $23.0 \pm 3.5^{a}$ & $30.0 \pm 3.2^{a}$ & $8.0 \pm 1.5$ & $F_{(3,19)}=11.1, P<0.001$ \\
\hline CA1 & $1.6 \pm .23(n=5)$ & $1.3 \pm .42$ & $0.71 \pm 0.23$ & $1.1 \pm 0.5$ & $F_{(3,19)}=0.913, P=\mathbf{0 . 4 5 3}$ \\
\hline CA2 & $0.38 \pm .19(n=5)$ & $0.52 \pm .18$ & $0.33 \pm 0.19$ & $0.06 \pm 0.06$ & $F_{(3,19)}=1.53, P=0.238$ \\
\hline CA3 & $4.6 \pm 1.4(n=5)$ & $3.4 \pm 1.2$ & $1.8 \pm 0.36$ & $1.6 \pm 0.41$ & $F_{(3,19)}=2.22, P=0.119$ \\
\hline DG & $15.5 \pm 2.4^{\mathrm{a}, \mathrm{b}}(n=5)$ & $17.7 \pm 2.8^{a, b}$ & $27.1 \pm 2.5^{a}$ & $5.2 \pm 0.84$ & $F_{(3,19)}=16.6, P<0.001$ \\
\hline aBNST & $84.0 \pm 30.1$ & $100.7 \pm 18.6$ & $160.1 \pm 29.8$ & $76.8 \pm 11.4$ & $F_{(3,20)}=2.52, P=0.087$ \\
\hline adBNST & $30.7 \pm 10.3^{b}$ & $42.22 \pm 5.8$ & $73.0 \pm 12.9^{a}$ & $22.7 \pm 3.3$ & $F_{(3,20)}=6.16, P<0.01$ \\
\hline avBNST & $53.3 \pm 20.4$ & $58.5 \pm 13.2$ & $87.1 \pm 19.6$ & $54.1 \pm 8.3$ & $F_{(3,20)}=0.98, P=0.418$ \\
\hline
\end{tabular}

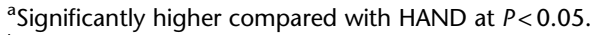

bSignificantly less than COND at $P<0.05$.

$n=6$, unless otherwise specified. Bold indicates significance between groups.

and Lattal 2019), in contrast to the relatively fast extinction to zero observed in rats in the present experiments and many others (Quirk et al. 2000; Anglada-Figueroa and Quirk 2005; Leung et al. 2007; Laurent and Westbrook 2008).

Although other studies have also found rapid reacquisition even after extensive extinction (e.g., Willcocks and McNally 2011), still others have found slow reacquisition after more extensive extinction (Bouton 1986; Bouton et al. 2004; Leung et al. 2007). It is possible that the rapid loss of conditioned responding during extinction in our experiments prevented extinction from strengthening. We observed very little spontaneous recovery after the first couple of extinction sessions, which may have prevented large prediction error-driven learning during the early parts of each subsequent extinction session, which is thought to be important for strengthening extinction (Wagner 1970; Rescorla 2000; Krupa and Thompson 2003; Sierra-Mercado et al. 2006; Leung and Westbrook 2008). However, it is notable that the second extinction session in Figures $1 \mathrm{~B}$ and $2 \mathrm{~B}$ appeared to result in weaker spontaneous recovery in groups receiving fewer extinction sessions compared to the more extensive extinction groups. It is not clear why this would occur, except that there may have been overall differences in the colony that could have contributed to lower levels of fear after one group had been extensively extinguished (Bredy and Barad 2008). It is hard to compare the second extinction session in the different groups because they occurred on different days to allow us to focus on common treatments during reconditioning and testing.

We attempted to manipulate the amount of spontaneous recovery that may occur by shortening the extinction session to allow for the more prolonged expression of the conditioned response in Experiment 4. Between-session differences in expression of fear did not affect reacquisition. Indeed, the literature is mixed in terms of the effects of expression of the conditioned response and extinction speed on the persistence of extinction, where expression and gradual extinction increases or does not affect extinction (e.g., Ouyang and Thomas 2005; Zimmerman and Maren 2010; Gershman et al. 2013).

It is also important to note that our initial conditioning procedure consisted of $2 \mathrm{~d}$ of conditioning, in which rats received four footshocks per day. Ricker and Bouton (1996) showed that conditioning procedures that require more conditioning sessions for acquisition favored rapid reacquisition following reconditioning due to sequential learning, which occurs when a CS-US pairing predicts further CS-US pairings due to extensive acquisition training (Capaldi 1994). Thus, our use of two 4 -shock conditioning sessions could favor rapid reacquisition and overcome the potentially impairing effect of massive extinction.

Additionally, the behavioral preparation here differed from a similarly conducted study that found that massive extinction impaired rapid reacquisition in Long-Evans rats (Leung et al. 2007). In the work by Leung et al. both conditioning and reconditioning sessions were a short 3 min context exposure with one shock (delivered $1 \mathrm{~min}$ into the session) and extinction was twice-daily with an extinction criterion requiring the absence of freezing across the initial minute of exposure. Perhaps procedural differences, such as weaker initial conditioning and twice-daily extinction sessions, led to changes in the strength of both conditioning and extinction memories that allowed rapid reacquisition to be impaired by massive extinction. The evidence of slow reacquisition found by the design in Leung et al. (2007) is relevant to the theory that additional trials during initial conditioning in Experiments 1 and 2 might have allowed sequential learning to favor rapid reacquisition in rats, regardless of the number of extinction sessions.

There are many other possible causes for rapid reacquisition. Similar to sequential learning, another possibility is that the shock becomes encoded as part of the acquisition context, meaning that a postextinction shock functionally serves to return the animals to the original context (Bouton 2002; Willcocks and McNally 2011), an account supported by the finding that intermittent CS-US pairings during extinction can slow reacquisition (Bouton et al. 2004) and presentation of outcomes associated with extinction can weaken resurgence (Trask and Bouton 2016). A related account would suggest that the shock delivered during reconditioning could have acted as a reminder of the original CS-US association and caused reinstatement of the fear behavior as opposed to an actual reconditioning of the CS-US association (Bouton and Bolles, $1979 b)$. Likewise, rapid reacquisition could be a result of a generalized enhancement of freezing behavior due to repeated exposure to shock. Rodents may have become sensitized to shock and exposure to further shock in any context could enhance fear learning, as in SEFL (Rau and Fanselow 2009). In Experiment 2, we found that a postextinction shock in a different context (Context $B$ ) from the conditioning and extinction contexts (Context A) did not cause increased freezing in the extinction context (Context A), but in Experiment 3 we found that this treatment did cause a generalized 
A
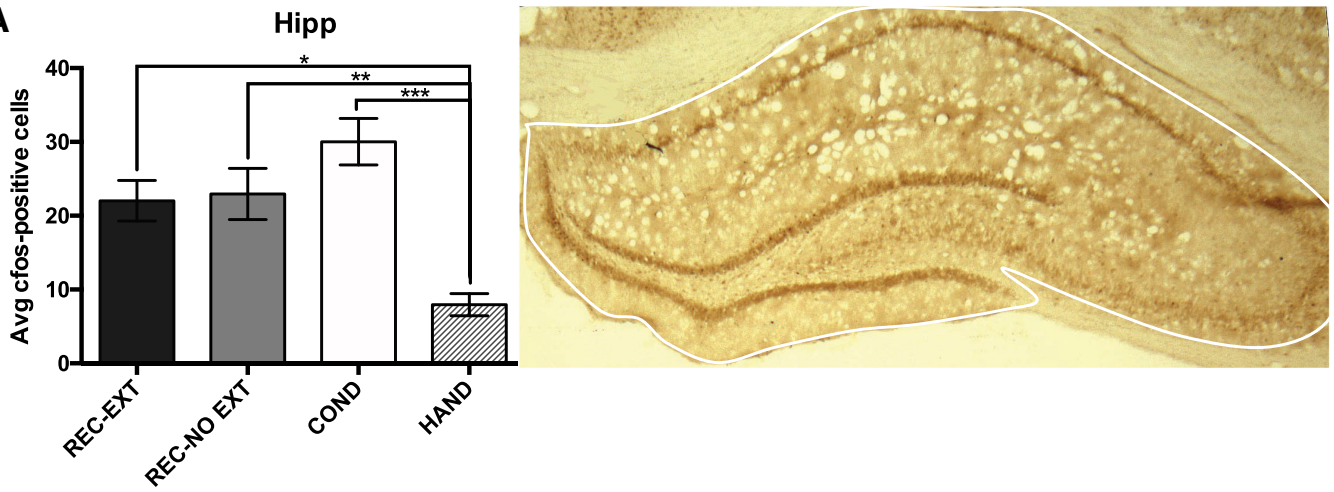

B
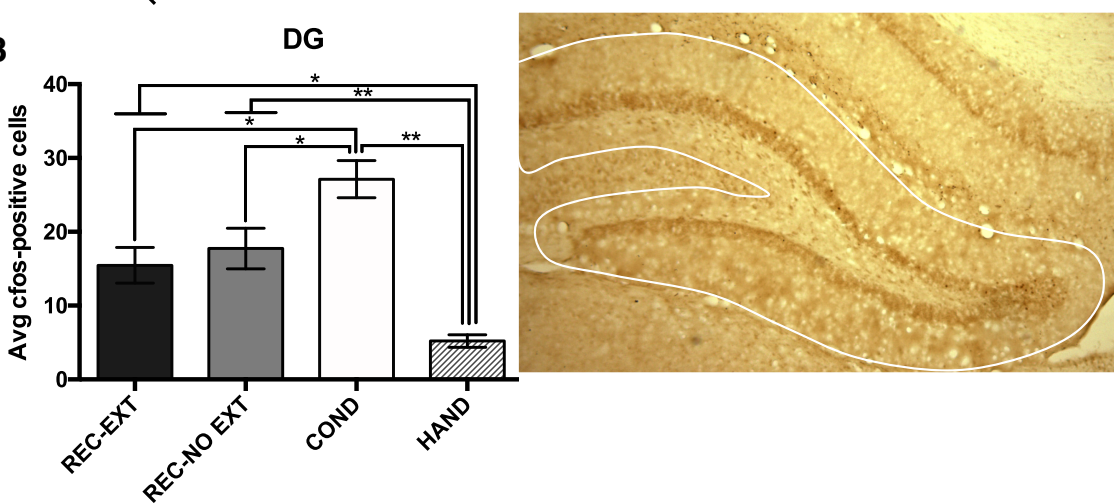

C

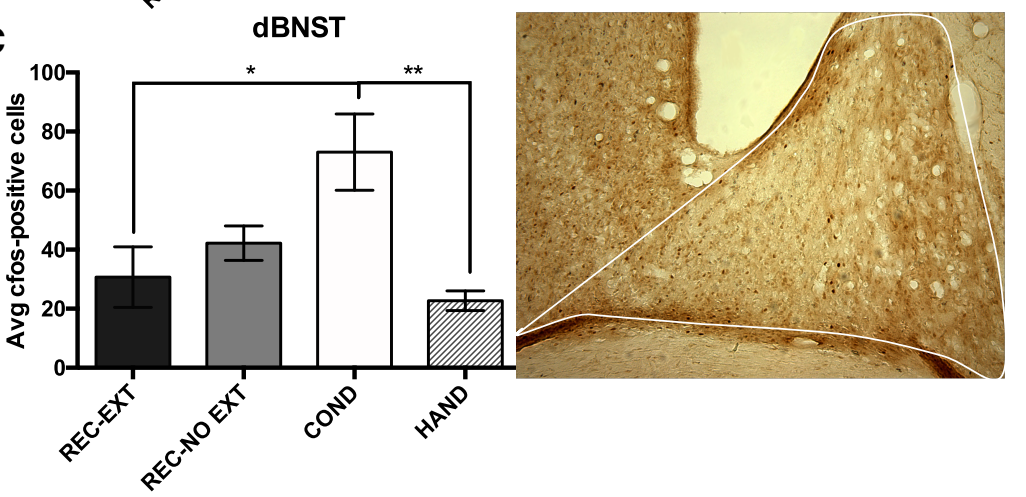

D

LA
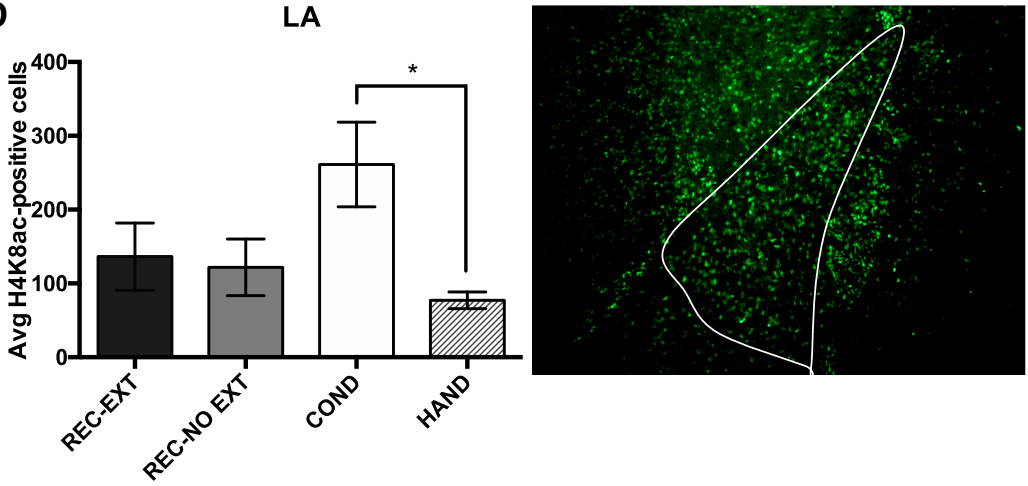

Figure 7. Acquisition leads to stronger activity marker expression than rapid reacquisition. $(A)$ The bar graph on the left shows the average c-Fos-positive cells within the entire dorsal hippocampus for each group. The image on the right shows a representative coronal slice of the hippocampus and the solid white line shows the region that was assessed for creating the average c-Fos-positive cell counts for analysis. ( $B$ ) A similar figure for the DG of the hippocampus. (C) A similar figure for the adBNST. (D) The bar graph on the left shows the average H4K8ac-positive cells within the lateral amygdala (LA) for each group. The panel on the right shows a representative coronal slice of the LA and the solid white line shows the region that was assessed for creating the average H4K8ac-positive cells. Significance between groups is represented by $\left({ }^{* *}\right)<0.001 ;\left({ }^{* *}\right) P<0.01 ;\left({ }^{*}\right) P<0.05$. Group numbers for each region are detailed in Tables 1, 2. Error bars represent standard error of the mean. 
Table 2. Mean \pm SEM of H4K8ac-positive cells in every region selected following Day 6

\begin{tabular}{|c|c|c|c|c|c|}
\hline & REC-EXT & REC-NO EXT & COND & HAND & ANOVA RESULTS \\
\hline$\overline{m P F C}$ & $273.6 \pm 80.1$ & $510.3 \pm 233.8,(n=5)$ & $645.8 \pm 253.4$ & $198.5 \pm 49.0,(n=4)$ & $F_{(3,17)}=0.788, P=0.517$ \\
\hline $\begin{array}{l}\text { IL } \\
\text { PrL }\end{array}$ & $\begin{array}{l}264.5 \pm 116.5 \\
245.8 \pm 117.5\end{array}$ & $\begin{array}{l}157.1 \pm 33.8 \\
153.3 \pm 42.3(n=5)\end{array}$ & $\begin{array}{l}324.5 \pm 122.7 \\
285.2 \pm 96.3\end{array}$ & $\begin{array}{l}115.2 \pm 33.3,(n=4) \\
121.8 \pm 34.5,(n=4)\end{array}$ & $\begin{array}{l}F_{(3,18)}=0.958, P=0.434 \\
F_{(3,17)}=0.677, P=0.578\end{array}$ \\
\hline $\begin{array}{l}\text { Amygdala } \\
\text { LA } \\
\text { BLA }\end{array}$ & $\begin{array}{l}\mathbf{1 3 6 . 1} \pm \mathbf{4 5 . 5} \\
146.8 \pm 56.4\end{array}$ & $\begin{array}{l}121.8 \pm 38.3,(n=4) \\
63.8 \pm 15.4,(n=4)\end{array}$ & $\begin{array}{l}\mathbf{2 6 1 . 3} \pm \mathbf{5 7 . 3 ^ { a }} \\
181.6 \pm 46.2\end{array}$ & $\begin{array}{l}\mathbf{7 7 . 2} \pm \mathbf{1 1 . 4} \\
81.42 \pm 20.8\end{array}$ & $\begin{array}{l}\boldsymbol{F}_{(\mathbf{3}, \mathbf{1 8})}=\mathbf{3 . 6 4}, P<\mathbf{0 . 0 5} \\
F_{(3,18)}=1.66, P=0.212\end{array}$ \\
\hline $\begin{array}{l}\text { dHipp } \\
\text { CA1 } \\
\text { CA2 } \\
\text { CA3 } \\
\text { DG }\end{array}$ & $\begin{array}{l}52.3 \pm 20.6(n=5) \\
16.6 \pm 9.9(n=5) \\
3.0 \pm 1.3(n=5) \\
2.3 \pm .2(n=5) \\
30.4 \pm 10.6(n=5)\end{array}$ & $\begin{array}{l}24.0 \pm 13.6(n=5) \\
2.7 \pm 1.6 \\
1.8 \pm 1.2(n=5) \\
1.7 \pm .7(n=5) \\
15.0 \pm 8.8\end{array}$ & $\begin{array}{l}66.1 \pm 40.0 \\
23.7 \pm 9.7 \\
4.5 \pm 2.6 \\
2.9 \pm 1.1 \\
40.4 \pm 26.9\end{array}$ & $\begin{array}{l}12.1 \pm 4.3 \\
2.1 \pm 0.7 \\
0.8 \pm 0.3 \\
1.2 \pm 0.5 \\
8.1 \pm 3.4\end{array}$ & $\begin{array}{l}F_{(3,18)}=1.06, P=0.390 \\
F_{(3,19)}=1.74, P=0.193 \\
F_{(3,18)}=0.99, P=0.419 \\
F_{(3,18)}=1.23, P=0.328 \\
F_{(3,19)}=0.90, P=0.459\end{array}$ \\
\hline $\begin{array}{l}\text { aBNST } \\
\text { adBNST } \\
\text { avBNST }\end{array}$ & $\begin{array}{l}530.0 \pm 116.3 \\
227.8 \pm 52.5 \\
302.2 \pm 69.0\end{array}$ & $\begin{array}{l}405.6 \pm 39.1 \\
185.4 \pm 19.8 \\
220.2 \pm 26.0\end{array}$ & $\begin{array}{l}610.8 \pm 162.4 \\
283.4 \pm 84.3 \\
327.3 \pm 83.2\end{array}$ & $\begin{array}{l}479.4 \pm 45.5 \\
191.3 \pm 22.2 \\
288.1 \pm 30.7\end{array}$ & $\begin{array}{l}F_{(3,20)}=0.685, P=0.572 \\
F_{(3,20)}=0.756, P=0.532 \\
F_{(3,20)}=0.631, P=0.603\end{array}$ \\
\hline
\end{tabular}

asignificantly higher compared with HAND at $P<0.05$.

$n=6$, unless otherwise specified. Bold indicates group differences.

increase in freezing in Context B, relative to groups receiving conditioning in Context B for the first time (i.e., a SEFL effect). Nonetheless, in both cases, the impact of the postextinction shock was the largest in the group that had received conditioning, extinction, and reconditioning all in the same context. This suggests that reconditioning occurs through associative processes that are not entirely due to sensitization or reinstatement from exposure to a postextinction shock.

Our experiments did not directly address some additional theoretical causes of rapid reacquisition: sequential learning, learning-to-learn, or the ability of rapid reacquisition to reactivate and strengthen the original excitatory memory. Yet, these experiments show that rapid reacquisition cannot be conflated with reinstatement to the US nor can it be considered a general enhancement in freezing to any context. Rapid reacquisition of contextual fear is likely its own unique phenomenon caused by CS-specific learning. Given these multiple accounts and other demonstrations that reconditioning and other postextinction processes differ at the behavioral level (e.g., Bouton et al. 2012; Willcocks and McNally 2014), it will be important to continue to characterize the behavioral effects of reconditioning.

At a neurobiological level, our immunohistochemistry results did not reveal that any of the structures we examined were specifically activated by postextinction reconditioning. When we did observe reliable group differences, the consistent finding was that initial conditioning resulted in more c-Fos expression and histone acetylation compared to handling controls. However, in some cases, reconditioning also elevated c-Fos expression above handling controls.

We found that the lateral subregion of the amygdala had greater H4K8 acetylation following weak initial acquisition than rapid reacquisition following extinction, reacquisition without extinction, and no-learning controls. An increase of H4K8ac following only acquisition suggests that this region was important for the molecular processes during and leading to the acquisition of a contextual fear memory. The lateral amygdala is a region known for being the entryway for sensory information that will be part of an associative memory (LeDoux et al. 1990; Maren and Quirk, 2004) and is necessary for cued and contextual fear conditioning (Goosens and Maren 2001), as well as extinction (e.g., Hobin et al. 2003; Laurent et al. 2008; Stafford et al. 2013). Particularly relevant to this finding, epigenetic processes, including histone acetylation, within the LA were critical for synaptic plasticity during and consolidation of fear (Monsey et al. 2011; Maddox et al. 2013; Kwapis et al. 2017). Given these findings and the LA's role as the sensory gateway for associative memories, the LA was likely to increase H4K8ac expression immediately following exposure of context-shock pairing.

We also found that the dorsal hippocampus, particularly the dentate gyrus region, was activated by conditioning and reconditioning. Many studies have shown the importance of the dorsal hippocampus in contextual fear conditioning and extinction (Phillips and LeDoux 1992; Lee and Kesner 2004; Corcoran et al. 2005; Stafford and Lattal 2009). Following the acquisition of contextual fear, markers like c-Fos show increased expression in the hippocampus (Huff et al. 2006) and hippocampal place cells show strong remapping to a context paired with shock in conditioning (Moita et al. 2004).

Our results showed that rapid reacquisition with and without prior extinction increased c-Fos expression in the dorsal hippocampus. Histone acetylation and c-Fos expression are involved in contextual fear and extinction (e.g., Stafford et al. 2012) and neurons within the dentate gyrus can be specifically associated with acquisition and extinction (Bernier et al. 2017). Additionally, many theorize that the hippocampus is a site important for indexing episodic memories and thus may be critical for relearning contextual fear in addition to initial learning (Teyler and Rudy 2007). Some studies have found that the hippocampus is necessary for rapid reacquisition for the memory of the spatial location of a food reward in a cross maze (Winocur et al. 2005) and molecular processes within the hippocampus are important for reacquisition of fear (Bevilaqua et al. 2005; Motanis and Maroun 2012).

The dentate gyrus was the site of most c-Fos-positive cells among the hippocampus subregions, suggesting the importance of the DG to contextual fear. Unlike the hippocampus as a whole, the DG had significantly more c-Fos expression following acquisition compared to both reacquisition groups, suggesting that the DG, in particular, was critical for contextual fear conditioning. The DG is critical for pattern separation (Treves and Rolls 1994) and is the best-known site of adult neurogenesis in rats (Altman and Das 1965). There has also been evidence that the DG is necessary for the retrieval of contextual fear (Lee and Kesner 2002, 2004). Further, the DG tags and recruits adult-generated neurons to update and strengthen remote spatial memories (Trouche et al. 2009). It is also possible that the c-Fos activation seen in the DG and hippocampus as a whole is due to spatial recognition and processing rather than specific to spatial learning. The hippocampus has shown the expression of IEG activity markers in tasks that are known to be hippocampal-independent (Guzowski 2002; Kubik et al. 2007), but spatial processing and spatial learning are 
intrinsically related and difficult to dissociate here. The inclusion of a handling control group mitigated some of the c-Fos expression due to nonlearning-specific hippocampal processes, but the handling animals were not exposed to the conditioning context and could not account for activation of place cells specific to the context. Thus, there are multiple mechanisms through which the hippocampus could be activated by conditioning and reconditioning.

The results for the BNST show that it is a region that is critical for both the acquisition and rapid reacquisition of contextual fear. First, the IHC showed that initial acquisition led to increased c-Fos-positive cells in the adBNST. The BNST has been implicated in fear and anxiety-like responding (Davis et al. 2010; Sink et al. 2013) and contextual fear conditioning (Sullivan et al. 2004; Waddell et al. 2006; Zimmerman and Maren 2011). There are different accounts for the role of the BNST in fear conditioning, including the idea that it is important for sustained fear responses that occur in response to long duration and unpredictable cues, or that it is involved in encoding prediction errors based on the temporal pattern of shock presentation (Fendt et al. 2003; Walker et al. 2003; Davis et al. 2010; Goode and Maren 2017). During contextual fear conditioning, the shock is not discretely signaled to cause animals to show sustained defensive behavior during continuous exposure with the best predictor of shock, the context. Thus, enhanced markers of activity in the BNST following contextual fear acquisition were expected, as the BNST as a whole had previously shown increased markers of metabolic activity following the expression of contextual fear (González-Pardo et al. 2012). Additionally, the adBNST is particularly important for anxiogenic behavior and stress responses (Herman et al. 1994; Kim et al. 2013).

Finally, it is important to note several caveats to using histone acetylation and c-Fos expression as markers of neuronal activity during reconditioning. First, a limitation with c-Fos is that its expression habituates after repeated exposure to inducible events like stress (Melia et al. 1994). Habituation may occur through either habituation of cellular expression of c-fos when a cell is reactivated by the same stimulus or by habituation of the population of cells activated by repeated stimulus presentation, such that the population of cells activated the second time is smaller (Melia et al. 1994; Watanabe et al. 1994; Girotti et al. 2006). Decreased c-Fos has been seen throughout the fear circuit following preexposure to a context, tone, or shock in cued fear conditioning (Radulovic et al. 1998). Thus, habituation could potentially occur during repeated context or shock exposure used in our experiments. This pitfall of c-Fos could also explain the findings in adBNST, as rapid reacquisition involved repeated exposure to the context and shock and could have habituated c-Fos expression. Extinction by its nature involves repeated exposure to a stimulus, so any postextinction phenomenon that is investigated is potentially impacted by c-Fos habituation. Our findings of reduced c-Fos expression in reconditioning relative to initial conditioning, therefore, need to be considered in the context of c-Fos habituation.

However, c-Fos did increase in the hippocampus following reacquisition. This outcome suggests that even if c-Fos did habituate, a region particularly important for contextual fear learning still revealed an effect. It will be important in future studies to investigate immediate-early genes that show less habituation with repeated treatment like $\Delta$ FosB (Kelz et al. 1999).

A caveat with using $\mathrm{H} 4 \mathrm{~K} 8$ acetylation as a measure of learning is that histone acetylation can be caused by different processes that involve transcriptional activation. For instance, H4K8ac is up-regulated in inflammation (Ashbrook et al. 2015) and antibody responses ( $\mathrm{Li}$ et al. 2013). This alternative could be represented in the H4K8ac results, where there was a very large magnitude of staining within the mPFC, amygdala, and dBNST. The massive $\mathrm{H} 4 \mathrm{~K} 8 \mathrm{ac}$ staining of these regions could have created a ceiling effect of expression that prevented the discernment of reliable group differences.

The research described here is significant for understanding how postextinction conditioning sessions can strengthen the original associative memory in a persistent manner. We show that, as with other unmasking procedures such as contextual renewal, rapid reconditioning is associative and appears to be unaffected by the amount of extinction (Bouton et al. 2011; Willcocks and McNally 2011). Our immunohistochemical results suggest that there are overlapping, but potentially unique brain regions that mediate initial conditioning and postextinction reconditioning. Finally, these sorts of results have implications at the clinical level, where PTSD symptoms often return with a mild reconditioning episode, even after successful treatment (Paunovic and Öst 2001; Pizzimenti and Lattal 2015). Rapid reconditioning, therefore, is a useful process to investigate at both basic science and translational levels.

\section{Materials and Methods}

\section{Animals and housing}

Experimentally naïve Male Long-Evans rats (Charles River Laboratories, Wilmington, MA) were purchased at 275-300 g ( 9-11 wk of age) and were housed two rats to an individually ventilated cage. Cagemates received the same experimental treatment on a given day (e.g., conditioning or extinction sessions), but they were sometimes in different counterbalanced context groups (in Experiments 2 and 3 ). Rats in all experiments were kept on a reverse $12 \mathrm{~h}$ light-dark schedule (dark started at 06:00 and light started at 18:00). Food and water were available ad libitum and all behavioral experiments occurred in the dark phase from 09:00 to 15:00. The colony space was located within a suite that included an anteroom and three procedure rooms for behavioral experiments.

All animals were allowed to acclimate to the vivarium at Oregon Health \& Science University (OHSU) for $7 \mathrm{~d}$ before any handling of behavioral procedures. The vivarium maintained a constant temperature $\left(22^{\circ} \mathrm{C} \pm 1^{\circ} \mathrm{C}\right)$ and humidity $(70 \%)$ in all animal rooms. All experimental procedures were approved by the OHSU Institutional Animal Use and Care Committee and were conducted in accordance with National Institutes of Health (NIH) "Principles of Laboratory Animal Care" (NIH Publication No. 86-23, revised 1985). Behavioral procedure rooms were within the same suite adjacent to the colony room.

\section{Apparatus}

\section{Context A (CTX A)}

Fear conditioning occurred in conditioning chambers (exterior dimensions: $31.8 \mathrm{~cm} \mathrm{~L} \times 25.4 \mathrm{~cm} \mathrm{~W} \times 26.7 \mathrm{~cm} \mathrm{H}$ ) housed within sound-attenuating chambers (Med Associates). The operant chambers were fixed with a grid floor set to deliver a $1 \mathrm{sec}, 0.75 \mathrm{~mA}$ scrambled shock and a house light that illuminated to signal the start of the session. Before and after each round of behavior, the grid floors and chamber walls were cleaned with 95\% ethanol. Animals were loaded into chambers in red light conditions to maintain the dark circadian cycle. For Experiments 2 and 3, the walls of the chamber were also fitted with horizontal black and white stripes to provide additional visual cues.

\section{Context B (CTX B)}

In Experiments 2 and 3, the second set of conditioning chambers were used as Context B. Context B differed from Context A in height $(31.8 \mathrm{~cm} \mathrm{~L} \times 25.4 \mathrm{~cm} \mathrm{~W} \times 34.3 \mathrm{~cm} \mathrm{H})$, visual cues (two clear Plexiglas walls; two metal walls), cleaning solution ( $0.5 \%$ bleach), and loading light conditions (full light). These chambers were also equipped with levers, cue lights, and food hoppers (all of which were inactive). The chambers were fixed with the same model grid floors as CTX A set to deliver a $1 \mathrm{sec}, 0.75 \mathrm{~mA}$ scrambled 
shock and a house light that illuminated to signal the start of the session.

\section{Habituation}

Prior to fear conditioning, all animals were habituated to transport to the anteroom and handling for $3 \mathrm{~d}$.

\section{Freezing assessment}

The level of contextual fear conditioning was assessed by the amount of freezing, the natural conditioned response to a context associated with shock (Bolles and Collier 1976). Freezing was hand scored by visual time sampling of each animal every $8 \mathrm{sec}$. The scorer was blind to treatment assignments except in cases where the differences were obvious (e.g., conditioning vs. extinction; different session durations).

\section{Contextual fear conditioning and extinction}

Rats were run through a modified version of the rapid reacquisition procedure we have previously used in mice (Williams and Lattal 2019). For all experiments, initial conditioning was a 12 -min session, in which rats received four unsignaled footshocks (1 sec, $0.75 \mathrm{~mA}$ ) at $2.5,5,9$, and $11.5 \mathrm{~min}$ into the session. Extinction consisted of a 24-min nonreinforced exposure to the fear-conditioning context in all experiments, except for Experiment 4 (see below). Reconditioning was a single conditioning session that consisted of 3 min session with a single unsignaled footshock $(1 \mathrm{sec}, 0.75$ $\mathrm{mA}$ ) delivered $2.5 \mathrm{~min}$ into the session. Postreconditioning tests were 24-min nonreinforced exposure to the fear-conditioning context. All sessions occurred at the same time of day separated by $24 \mathrm{~h}$.

\section{Experiment 1: reconditioning after 2 or 12 extinction sessions}

Twenty-four rats were divided into three groups: reconditioning following 12 extinction sessions (Group REC 12 EXT), reconditioning following two extinction sessions (Group REC 2 EXT), and initial conditioning (COND). All treatments occurred in Context A.

REC 12 EXT received conditioning on Days 1 and 2 (Phase 1) followed by 12 days of extinction on Days 3 to 14 (Phase 2). REC 2 EXT received conditioning on Days 11 and 12 (Phase 1) and extinction on days 13 and 14 (Phase 2). This behavioral schedule allowed groups to receive different amounts of extinction (12 vs. $2 \mathrm{~d}$ ), but have the final 2 extinction sessions, reconditioning, and testing on the same days.

Day 15 was a reconditioning session (Phase 3 ) followed by the postreconditioning tests on Days 16 and 19 (Phase 4). The behavioral schedule is summarized in Figure 1A. All tests were $24 \mathrm{~min}$.

\section{Experiment 2: effects of a postextinction US in a different context}

Thirty-two rats were subdivided into four groups that received different treatments: reconditioning following 3 sessions of extinction (Group REC 3 EXT, $n=8$ ), reconditioning following 6 sessions of extinction (Group REC 6 EXT, $n=8$ ), reconditioning in a different context following moderate extinction (Group SWITCH 3 EXT, $n=8$ ), and conditioning with the single shock for the first time (Group COND, $n=8$ ). The context was counterbalanced in each group, with half of each group run in CTX A ( $n=4 /$ group) and CTX B ( $n=4 /$ group) as their original conditioning context. For the purposes of the simplified behavioral schedule in Figure 1A and the discussion of the methods and results, the original context is referred to as CTX A and switched context is CTX B.

\section{Phase 1: conditioning}

Days 1 and 2 (Conditioning) consisted of conditioning sessions (12 min, four footshocks) for Group REC 6 EXT in CTX A. All other groups were transported to the anteroom and handled. On Days
4 and 5, Groups REC 3 EXT and SWITCH 3 EXT received conditioning in CTX A.

\section{Phase 2: extinction}

Twenty-four minutes extinction sessions occurred on Days 3 to 8 (REC 6 EXT) or Days 6 to 8 (REC 3 EXT and SWITCH 3 EXT) in CTX A. This behavioral schedule allowed the extinction groups to receive different amount of extinction ( 6 vs. $3 \mathrm{~d}$ of extinction), followed by reconditioning and testing on the same days.

\section{Phase 3: reconditioning}

All groups received reconditioning on Day 9. For groups REC 3 EXT and REC 6 EXT, reconditioning occurred in CTX A. For SWITCH 3 EXT, reconditioning occurred in CTX B.

\section{Phase 4: tests}

Day 10 was a postreconditioning test in the original conditioning context (CTX A; Test 1) and Day 11 was a test in the switched context for all groups (CTX B; Test 2). On Day 12, another postreconditioning test occurred in the original context (CTX A; Test 3 ) to test for long-term retention. Tests 1 and 2 were $24 \mathrm{~min}$ and Test 3 was $12 \mathrm{~min}$.

\section{Experiment 3: reconditioning with matched US and context exposure}

Thirty-two rats were subdivided into four groups ( $n=8$ /group). Group REC SAME received 2 sessions of initial conditioning (four shocks in $12 \mathrm{~min}$, as in Experiments 1 and 2) and 3 sessions of extinction (nonreinforced 24-min context exposures) in Context A; Group REC DIFF received conditioning and extinction in Context B; Group COND SAME received equivalent nonreinforced exposure to Context A (matched to acquisition durations of two 12-min exposures and extinction durations of three 24-min exposures); Group COND DIFF received an identical amount of nonreinforced exposure to Context B. Twenty-four hours after the final extinction/context exposure session, all groups received a single weak conditioning session in Context A ( 3 min exposure with a shock after $2.5 \mathrm{~min}$, as in Experiments 1 and 2). All groups received a nonreinforced 24-min test session in Context A $24 \mathrm{~h}$ after the weak conditioning session. The identities of Contexts A and B were counterbalanced.

\section{Experiment 4: reconditioning after short or long extinction sessions}

Sixteen male naïve Long-Evans rats on a Long-Evans Th-Cre ${ }^{+/}$ background were used in this experiment separated into two groups that differed in extinction session length: reconditioning following 24-min extinction sessions (24 MIN, similar to reconditioning groups above) and reconditioning following 6 min extinction sessions (6 MIN).

Days 1 and 2 consisted of conditioning (Phase 1). For Group 24 MIN, Days 3 to 6 consisted of extinction training as described above ( $24 \mathrm{~min}$ of exposure to the context without shock). For Group $6 \mathrm{MIN}$, Days 3 to 6 also consisted of extinction, but these sessions were only 6 min of nonreinforced context exposure.

Day 7 was the reconditioning session (Phase 3) followed by the postreconditioning test on Day 8 for all groups (Phase 4). The behavioral schedule is outlined in Figure 4A.

\section{Experiment 5: immunohistochemical characterization of rapid reconditioning}

\section{Methods}

Animals and housing. Twenty-four male Long-Evans rats were purchased at 275-300 g ( 9-11 wk of age) and were housed two rats to an individually ventilated cage. 


\section{Behavior}

Behavioral schedule. For all experiments, conditioning was a 12-min session, in which rodents received four unsignaled footshocks ( $1 \mathrm{sec}, 0.75 \mathrm{~mA}$ ) at $2.5,5,9$, and $11.5 \mathrm{~min}$ into the session. Extinction consisted of a 24-min nonreinforced exposure to the fear-conditioning context. Reconditioning was a weak conditioning session consisting of 3 min session with a single unsignaled footshock ( $1 \mathrm{sec}, 0.75 \mathrm{~mA}$ ) delivered $2.5 \mathrm{~min}$ into the session. All sessions were conducted at the same time of day separated by $24 \mathrm{~h}$.

There were four groups that differed in conditioning history: reconditioning after 3 sessions of extinction (REC-EXT, $n=6$ ), reconditioning after no extinction (REC-NO EXT, $n=6$ ), conditioning only (COND, $n=8$ ), and a handled, behavior-naïve group (HAND, $n=6$ ). The full behavioral schedule is detailed in Figure $5 \mathrm{~A}$.

Phase 1: conditioning. Days 1 and 2 consisted of a conditioning sessions for REC-EXT and REC-NO EXT. All other groups were handled and transported to equate treatments.

Phase 2: extinction. On Days 3 to 5, REC-EXT received extinction training, while REC-NO EXT was handled and returned to the homecage without extinction training.

Phase 3: reconditioning. All groups received reconditioning, as described above, on Day 6. For groups REC-EXT and REC-NO EXT, Day 6 was a reconditioning session, but for COND this day was its first conditioning and exposure to the context. HAND was handled and returned to the homecage as in all previous phases. Fifty to ninety minutes following the end of Phase 3 all animals were sacrificed and perfused for brain collection.

\section{Brain removal and cryoprotection}

Animals were sacrificed via isoflurane until all breathing had stopped and then thoracotomy was used as a secondary form of euthanasia. Rats were then perfused with $4 \%$ paraformaldehyde (PFA) and phosphate-buffered serum (PBS). Brains were removed and placed in $4 \%$ PFA in PBS for no more than $24 \mathrm{~h}$. For cryoprotection, brains were then placed in a solution of $20 \%$ sucrose and $0.1 \%$ sodium azide $\left(\mathrm{NaN}_{3}\right)$ in PBS until the brain was fully saturated with sucrose (generally $24 \mathrm{~h}$ ). The brains were then transferred to $30 \%$ sucrose and $0.1 \% \mathrm{NaN}_{3}$ in PBS for no more than 1 mo before sectioning. The brains were sectioned at 35 microns and then placed in well plates of PBS and $0.1 \% \mathrm{NaN}_{3}$ until further processing via immunohistochemistry.

\section{Immunohistochemistry (IHC)}

Materials. Rabbit anti c-Fos IgG (F7799, Sigma-Aldrich, Saint Louis, MO) and goat anti-rabbit biotinylated IgG antibodies (BA-1000, Vector Laboratories) were purchased for c-Fos detection. Vectastain ABC Kit (PK-400, Vector Laboratories) and Metal Enhanced Diaminobenzidine (DAB) Kit (PI-34064, Fischer Scientific) were used for immunoreaction detection.

Rabbit anti H4K8 Acetyl-Histone H4 Lys8 (2594S, Cell Signaling, Danvers, MA) and goat anti-rabbit IgG F(ab')2-Alexa Fluor 488 (Thermo Fisher Scientific) antibodies were purchased for H4K8ac histone acetylation detection.

Tissue selection for processing. Due to a large amount of tissue collected to include all regions of interest, not all of the tissue could be processed at once and multiple rounds of IHC were run. To have a balanced representation, tissue was processed by region in which all animals were included (e.g., every other slice of mPFC for each animal was processed simultaneously).

$D A B I H C$ schedule. Procedures followed those described by Weitemier and Ryabinin (2004). All incubations were done at room temperature on a plate rotating at $\sim 40 \mathrm{rpm}$. Slices in 12 well plates and net wells were first treated with $3 \times 5$ min washes in PBS to wash away $\mathrm{NaN}_{3}$. A 15 min incubation in $0.3 \%$ hydrogen peroxide in PBS blocked endogenous peroxidase activity and was followed by three additional PBS washes. The slices were then incubated in a blocking solution for $4 \mathrm{~h}$, which consisted of a 1:10 solution of normal goat serum (NGS, S-1000, Vector Laboratories) into $0.1 \%$ triton in PBS (PBS/Triton). NGS was the blocker of choice in these molecular assays due to the animal (goat) in which the secondary antibody was raised. Following blocking, the slices were in- cubated overnight $(\sim 15 \mathrm{~h})$ in primary antibody, anti c-Fos rabbit IgG, that was at a concentration of 1:15000 in PBS/Triton/bovine serum albumin (BSA).

The following day commenced with $3 \times 5$ min PBS washes and subsequently with the secondary antibody incubation. The secondary antibody solution consisted of 1:200 concentration of biotinylated goat anti-rabbit IgG in PBS/Triton. This incubation lasted for $1 \mathrm{~h}$ and was followed with $3 \times 5$ min PBS washes.

Next, a Vectastain ABC kit was used to bind to secondaryantibody-bound cells via a biotin/avidin interaction. The $\mathrm{ABC}$ solution was a 1:200 concentration of both chemicals A (avidin) and B (biotin; the exact composition of which is proprietary information) into PBS/triton. This mixture was made $30 \mathrm{~min}$ prior to application and the incubation lasted for $1 \mathrm{~h}$. This step was followed by PBS washes and the application of a $1 \times$ solution of diaminobenzidine (DAB) in peroxidase $\left(\mathrm{H}_{2} \mathrm{O}_{2}\right)$ buffer that provided intense coloration of immunopositive cells. Unlike previous steps, this incubation was not done on the rotating plate. The incubation time in $\mathrm{DAB}$ was around $1 \mathrm{~min}$, a time chosen from pilot data for the optimal for strong signal and minimal background (data not shown). This incubation time was kept consistent for all plates. Immediately after $\mathrm{DAB}$ incubation, the wells were placed into the ultraviolet (UV) purified water to stop the reaction and prevent the tissue from saturating.

The slices were then placed onto glass Superfrost slides (Fisher Scientific) via a mounting solution (composed of UV purified water, gelatin, acetic acid, and 95\% ethanol) and allowed to dry overnight. After drying, the slides were dehydrated in sequential steps of ethanol at increasing concentrations: $10 \mathrm{~min}$ in $70 \%, 95 \%$, and then $100 \%$ ethanol. Next, the slides were dehydrated in the final step by submersion into Citrasolv (Fisher Scientific) and immediately coverslipped with glass covers and Cytoseal 60 mounting media (Fisher Scientific).

Fluorescent IHC schedule. Fluorescent IHC was similarly run as DAB IHC above with several exceptions. Well plate IHC was employed again and slices were first treated with $3 \times 10$ min washes in $0.1 \mathrm{M}$ Tris washes to wash away $\mathrm{NaN}_{3}$. Slices were then incubated in 1\% sodium borohydride in Tris for $30 \mathrm{~min}$ followed by Tris washes (at least three washes) until the sodium borohydride reaction was removed. Prior to the primary antibody, blocking was performed by incubating the slices in 5\% NGS in a $0.3 \%$ Triton-Tris solution for $45 \mathrm{~min}$. Then, slices received an overnight incubation in the primary antibody, 1:1000 rabbit anti H4K8ac, in Triton-Tris and $1 \%$ NGS.

The following day, the primary antibody was washed away in $3 \times 10 \mathrm{~min}$ Tris washes. Another round of blocking (45 min in 5\% NGS) occurred prior to secondary antibody incubation. The secondary antibody incubation was $1 \mathrm{~h}$ submersion in 1:1000 goat anti-rabbit Alexa Fluor 488 and 5\%NGS in Triton-Tris. During and following the secondary antibody, slices were protected from light at all times. The slices were then washed in Tris and $3 \times 5$ min in PBS. Following washes, slices were mounted on glass Superfrost slides in the mounting solution used above. Slices were not dehydrated, but instead cover-slipped with Vectashield mounting medium with DAPI (H-1200, Vector Laboratories) shortly after mounting on the slide. DAPI labeled the neurons with a fluorescence of $360 \mathrm{~nm}$.

Tissue imaging and cell counting. The processed tissue was imaged using the Leica DM4000B microscope (Leica Microsystems Inc.) on brightfield settings for $\mathrm{DAB}$ or with laser light set to excite Alexa Fluor 488 for fluorescent markers. Each image was taken at a consistent intensity, field diaphragm, aperture, and magnification for each image and region $(I=8 ; A=25 ; \mathrm{FD}=32$ for $\mathrm{DAB}$ and $I=100 ; \mathrm{FD}=6 ; \Sigma=100 \times$ for fluorescence). All images used for cell counting were taken with a $10 \times$ objective, except for the hippocampus, which required a $5 \times$ objective to capture the region. Each image was collected using QImage Micro-Publisher 3.3 RTV camera and software (QImaging) at the same exposure (exposure $=84.1 \mathrm{msec}$ for $\mathrm{DAB}$ and exposure $=1.87$ for fluorescence). 
Each image was analyzed using ImageJ software (NIH). The images were adjusted through a threshold procedure, in which images were converted to an 8-bit image prior to the application of a threshold mask. The threshold mask was chosen using neighboring brain regions with only nonspecific background staining as control regions. A consistent threshold range (for DAB, 80-120; for fluorescence, $20-50$ on a dark background) and circularity $(0.7-1.00)$ were used throughout the regions. The lower limit of pixels required for a stained cell depended on the region, but was consistent within each region (60 pixels for mPFC regions, 50 pixels for amygdala and BNST, and 15 pixels for the hippocampus because the images were at a lower magnification).

Both whole regions (expect the amygdala) and subregions were analyzed for group differences. The chosen location (relative to bregma) for each subregion was: IL (3.00 mm); PrL (3.35 mm); adBNST_-dorsal subregion of anterior BNST $(0.00 \mathrm{~mm})$; avBNST -ventral subregion of anterior BNST $(0.00 \mathrm{~mm})$; CeA $(-2.76$ $\mathrm{mm})$; BLA $(-2.76 \mathrm{~mm}) ; \mathrm{LA}(-2.76 \mathrm{~mm})$; CA1 $(-3.00 \mathrm{~mm})$; CA2 $(-3.00 \mathrm{~mm})$; CA3 $(-3.00 \mathrm{~mm})$; DG $(-3.00 \mathrm{~mm})$. The PaxinosWatson rat atlas was used to confirm the bregma location of slices and only slices within $0.35 \mathrm{~mm}$ of the bregma location listed above were considered for assessment of staining. Two to four slices were counted and averaged for each animal to get the average amount of target protein expression captured by IHC. Due to the loss of integrity of the tissue of a few animals, the total numbers of animals per group for each region are shown in Tables 1 and 2. For H4K8ac analyses, the CeA tissue was too degraded to include in analyses.

\section{Statistics}

R-Studio and GraphPad Software Prism 6 were used to run all statistics and create figures, respectively. Extinction sessions were generally analyzed by mixed analysis of variance (ANOVA) in which Group was the between subjects measure, and Extinction Session and Session Time Block were the within-subjects factors. Reconditioning was analyzed with a two-way RMANOVA comparing the average percent freezing in the 30 sec pre- and postshock (Time) by Group. Test sessions were analyzed with a one-way ANOVA (or $t$-test, if applicable) with percent freezing in time blocks within the session as the dependent measure and Group as the main factor. c-Fos or H4K8ac detection was analyzed with a oneway ANOVA with Group as the main factor and average protein counts per animal as the dependent measure. Any failure to meet the homogeneity of variances criterion for an ANOVA or $t$-test (as measured by the Brown-Forsythe Levene's test) was accounted for using a Welch correction. If significance was found for main effects or interactions, Tukey's HSD tests (or Games-Howell for unequal variances among groups) were used for simple comparisons between groups and sessions. For all statistical tests, significance was set at $\alpha=0.05$.

\section{Acknowledgments}

This paper was supported by National Institutes of Health (NIH) grants T32AA007468 (A.R.W.), R01DA025922 (K.M.L.), R21MH106284 (K.M.L.), and DOD TATRC W81XWH-14-2-0143 (K.M.L.).

\section{References}

Alheid GF, Heimer L. 1988. New perspectives in basal forebrain organization of special relevance for neuropsychiatric disorders: the striatopallidal, amygdaloid, and corticopetal components of substantia innominata. Neuroscience 27: 1-39. doi:10.1016/0306-4522(88)90217-5

Alheid GF, DeOlmos CA, Beltramino CA. 1995. Amygdala and extended amygdala. In The rat nervous system, 2nd ed. (ed. Paxinos G), pp. 495578. Wiley/Blackwell, San Diego.

Altman J, Das GD. 1965. Autoradiographic and histological evidence of postnatal hippocampal neurogenesis in rats. J Comp Neurol 124: 319335. doi:10.1002/cne.901240303

Anglada-Figueroa D, Quirk GJ. 2005. Lesions of the basal amygdala block expression of conditioned fear but not extinction. J Neurosci 25: 96809685. doi:10.1523/jneurosci.2600-05.2005
Ashbrook MJ, McDonough KL, Pituch JJ, Christopherson PL, Cornell TT, Selewski DT, Shanley TP, Blatt NB, 2015. Citrate modulates lipopolysaccharide-induced monocyte inflammatory responses. Clin Exp Immunol 180: 520-530. doi:10.1111/cei.12591

Bernier BE, Lacagnina AF, Ayoub A, Shue F, Zemelman BV, Krasne FB, Drew MR. 2017. Dentate gyrus contributes to retrieval as well as encoding: evidence from context fear conditioning, recall, and extinction. J Neurosci 37: 6359-6371. doi:10.1523/JNEUROSCI.3029-16 .2017

Bevilaqua LRM, da Silva WN, Medina JH, Izquierdo I, Cammarota M. 2005. Extinction and reacquisition of a fear-motivated memory require activity of the Src family of tyrosine kinases in the CA1 region of the hippocampus. Pharmacol Biochem Behav 81: 139-145. doi:10.1016/j.pbb .2005.03.005

Bolkan SS, Lattal KM. 2014. Opposing effects of D-cycloserine on fear despite a common extinction duration: interactions between brain regions and behavior. Neurobiol Learn Mem 113: 25-34. doi:10.1016/j .nlm.2013.12.009

Bolles RC, Collier AC. 1976. The effect of predictive cues on freezing in rats. Anim Learn Behav 4: 6-8. doi:10.3758/BF03211975

Bouton ME. 1986. Slow reacquisition following the extinction of conditioned suppression. Learn Motiv 17: 1-15. doi:10.1016/0023-9690 (86) $90017-2$

Bouton ME. 2002. Context, ambiguity, and unlearning: sources of relapse after behavioral extinction. Biol Psychiatry 52: 976-986. doi:10.1016/ S0006-3223(02)01546-9

Bouton ME, Bolles RC. 1979a. Contextual control of the extinction of conditioned fear. Learn Motiv, 10: 445-466. doi:10.1016/0023-9690(79) 90057-2

Bouton ME, Bolles RC. 1979b. Role of conditioned contextual stimuli in reinstatement of extinguished fear. J Exp Psychol Anim Behav Process 5: 368-378. doi:10.1037/0097-7403.5.4.368

Bouton ME, Swartzentruber D. 1989. Slow reacquisition following extinction: context, encoding, and retrieval mechanisms. J Exp Psychol Anim Behav Process 15: 43-53. doi:10.1037/0097-7403.15.1.43

Bouton ME, Woods AM, Pineño O. 2004. Occasional reinforced trials during extinction can slow the rate of rapid reacquisition. Learn Motiv, 35: 371390. doi:10.1016/j.lmot.2004.05.001

Bouton ME, Todd TP, Vurbic D, Winterbauer NE. 2011. Renewal after the extinction of free operant behavior. Learn Behav 39: 57-67. doi:10.3758/ s13420-011-0018-6

Bouton ME, Winterbauer NE, Todd TP. 2012. Relapse processes after the extinction of instrumental learning: renewal, resurgence, and reacquisition. Behav Processes 90: 130-141. doi:10.1016/j.beproc.2012 .03 .004

Bredy TW, Barad M. 2008. Social modulation of associative fear learning by pheromone communication. Learn Mem 16: 12-18. doi:10.1101/lm .1226009

Brooks DC, Bowker JL, Anderson JE, Palmatier MI. 2003. Impact of brief or extended extinction of a taste aversion on inhibitory associations: evidence from summation, retardation, and preference tests. Learn Behav 31: 69-84. doi:10.3758/BF03195971

Capaldi EJ. 1994. The sequential view: from rapidly fading stimulus traces to the organization of memory and the abstract concept of number. Psychon Bull Rev 1: 156-181. doi:10.3758/BF03200771

Corcoran KA, Desmond TJ, Frey KA, Maren S. 2005. Hippocampal inactivation disrupts the acquisition and contextual encoding of fear extinction. J Neurosci 25: 8978-8987. doi:10.1523/JNEUROSCI.2246-05 .2005

Crabbe JC, Schlumbohm JP, Hack W, Barkley-Levenson AM, Metten P, Lattal KM. 2016. Fear conditioning in mouse lines genetically selected for binge-like ethanol drinking. Alcohol 52: 25-32. doi:10.1016/j alcohol.2016.01.004

Davis M, Walker DL, Miles L, Grillon C. 2010. Phasic vs sustained fear in rats and humans: role of the extended amygdala in fear vs anxiety. Neuropsychopharmacology 35: 105-135. doi:10.1038/npp.2009.109

Deschaux O, Motanis H, Spennato G, Moreau JL, Garcia R. 2011. Re-emergence of extinguished auditory-cued conditioned fear following a sub-conditioning procedure: effects of hippocampal and prefrontal tetanic stimulations. Neurobiol Learn Mem 95: 510-518. doi:10.1016/j nlm.2011.03.002

Erb S, Stewart J. 1999. A role for the bed nucleus of the stria terminalis, but not the amygdala, in the effects of corticotropin-releasing factor on stress-induced reinstatement of cocaine seeking. J Neurosci 19: RC35. doi:10.1523/JNEUROSCI.19-20-j0006.1999

Fendt M, Endres T, Apfelbach R. 2003. Temporary inactivation of the bed nucleus of the stria terminalis but not of the amygdala blocks freezing induced by trimethylthiazoline, a component of fox feces. J Neurosci 23: 23-28. doi:10.1523/JNEUROSCI.23-01-00023.2003

Fu J, Xing X, Han M, Xu N, Piao C, Zhang Y, Zheng X. 2016. Region-specific roles of the prelimbic cortex, the dorsal CA1, the ventral DG and ventral CA1 of the hippocampus in the fear return evoked by a sub-conditioning 
procedure in rats. Neurobiol Learn Mem 128: 80-91. doi:10.1016/j.nlm .2015 .12 .006

Gershman SJ, Jones CE, Norman KA, Monfils M-H, Niv Y. 2013. Gradual extinction prevents the return of fear: implications for the discovery of state. Front Behav Neurosci 7: 164. doi:10.3389/fnbeh.2013.00164

Girotti M, Pace TWW, Gaylord RI, Rubin BA, Herman JP, Spencer RL. 2006. Habituation to repeated restraint stress is associated with lack of stress-induced c-fos expression in primary sensory processing areas of the rat brain. Neuroscience 138: 1067-1081. doi:10.1016/j.neuroscience .2005 .12 .002

González-Pardo H, Conejo NM, Lana G, Arias JL. 2012. Different brain networks underlying the acquisition and expression of contextual fear conditioning: a metabolic mapping study. Neuroscience 202: 234-242. doi:10.1016/j.neuroscience.2011.11.064

Goode TD, Maren S. 2014. Animal models of fear relapse. ILAR J 55: 246258. doi:10.1093/ilar/ilu008

Goode TD, Maren S. 2017. Role of the bed nucleus of the stria terminalis in aversive learning and memory. Learn Mem 24: 480-491. doi:10.1101/lm .044206 .116

Goode TD, Kim JJ, Maren S. 2015. Reversible inactivation of the bed nucleus of the stria terminalis prevents reinstatement but not renewal of extinguished fear. eNeuro 2: ENEURO.0037-15.2015. doi:10.1523/ ENEURO.0037-15.2015

Goosens KA, Maren S. 2001. Contextual and auditory fear conditioning are mediated by the lateral, basal, and central amygdaloid nuclei in rats. Learn Mem 8: 148-155. doi:10.1101/lm.37601

Guzowski JF. 2002. Insights into immediate-early gene function in hippocampal memory consolidation using antisense oligonucleotide and fluorescent imaging approaches. Hippocampus 12: 86-104. doi:10 $.1002 /$ hipo. 10010

Hart JA, Bourne MJ, Schachtman TR. 1995. Slow reacquisition of a conditioned taste aversion. Anim Learn Behav 23: 297-303. doi:10.3758/ BF03198926

Hart G, Holmes NM, Harris JA, Westbrook RF. 2014. Benzodiazepine administration prevents the use of error-correction mechanisms during fear extinction. Learn Behav 42: 383-397. doi:10.3758/ s13420-014-0155-9

Herman JP, Cullinan WE, Watson SJ. 1994. Involvement of the bed nucleus of the stria terminalis in tonic regulation of paraventricular hypothalamic CRH and AVP mRNA expression. J Neuroendocrinol 6: 433442. doi:10.1111/j.1365-2826.1994.tb00604.x

Hobin JA, Goosens KA, Maren S. 2003. Context-dependent neuronal activity in the lateral amygdala represents fear memories after extinction. J Neurosci 23: 8410-8416. doi:10.1523/JNEUROSCI .23-23-08410.2003

Huff NC, Wright-Hardesty KJ, Higgins EA, Matus-Amat P, Rudy JW. 2005. Context pre-exposure obscures amygdala modulation of contextual-fear conditioning. Learn Mem 12: 456-460. doi:10.1101/lm.6705

Huff NC, Frank M, Wright-Hardesty K, Sprunger D, Matus-Amat P, Higgins E, Rudy JW. 2006. Amygdala regulation of immediate-early gene expression in the hippocampus induced by contextual fear conditioning. J Neurosci 26: 1616-1623. doi:10.1523/JNEUROSCI .4964-05.2006

Kelz MB, Chen J, Carlezon WA, Whisler K, Gilden L, Beckmann AM, Steffen C, Zhang YJ, Marotti L, Self DW, et al. 1999. Expression of the transcription factor deltaFosB in the brain controls sensitivity to cocaine. Nature 401: 272-276. doi:10.1038/45790

Kim M, Davis M. 1993. Electrolytic lesions of the amygdala block acquisition and expression of fear-potentiated startle even with extensive training but do not prevent reacquisition. Behav Neurosci 107: 580-595. doi:10 $.1037 / 0735-7044.107 .4 .580$

Kim S-Y, Adhikari A, Lee SY, Marshel JH, Kim CK, Mallory CS, Lo M, Pak S, Mattis J, Lim BK, et al. 2013. Diverging neural pathways assemble a behavioural state from separable features in anxiety. Nature 496: 219223. doi:10.1038/nature12018

Krupa DJ, Thompson RF. 2003. Inhibiting the expression of a classically conditioned behavior prevents its extinction. J Neurosci 23: 1057710584. doi:10.1523/jneurosci.23-33-10577.2003

Kubik S, Miyashita T, Guzowski JF. 2007. Using immediate-early genes to map hippocampal subregional functions. Learn Mem 14: 758-770. doi:10.1101/lm.698107

Kwapis JL, Alaghband Y, López AJ, White AO, Campbell RR, Dang RT, Rhee D, Tran AV, Carl AE, Matheos DP, et al. 2017. Context and auditory fear are differentially regulated by HDAC3 activity in the lateral and basal subnuclei of the amygdala. Neuropsychopharmacology 42: 1284. doi:10.1038/npp.2016.274

Lattal KM, Maughan DK. 2012. A parametric analysis of factors affecting acquisition and extinction of contextual fear in C57BL/ 6 and DBA/2 mice. Behav Processes 90: 49-57. doi:10.1016/j.beproc.2012.03.008

Laurent V, Westbrook RF. 2008. Distinct contributions of the basolateral amygdala and the medial prefrontal cortex to learning and relearning extinction of context conditioned fear. Learn Mem 15: 657-666. doi:10 $.1101 / \mathrm{lm} .1080108$

Laurent V, Westbrook RF. 2009. Infusion of the NMDA receptor antagonist, DL-APV, into the basolateral amygdala disrupts learning to fear a novel and a familiar context as well as relearning to fear an extinguished context. Learn Mem 16: 96-105. doi:10.1101/lm.1218709

Laurent V, Marchand AR, Westbrook RF. 2008. The basolateral amygdala is necessary for learning but not relearning extinction of context conditioned fear. Learn Mem 15: 304-314. doi:10.1101/lm.928208

LeDoux JE, Cicchetti P, Xagoraris A, Romanski LM. 1990. The lateral amygdaloid nucleus: sensory interface of the amygdala in fear conditioning. J Neurosci 10: 1062-1069. doi:10.1523/JNEUROSCI .10-04-01062.1990

Lee Y, Davis M. 1997. Role of the hippocampus, the bed nucleus of the stria terminalis, and the amygdala in the excitatory effect of corticotropin-releasing hormone on the acoustic startle reflex. J Neurosci 17: 6434-6446. doi:10.1523/jneurosci.17-16-06434.1997

Lee I, Kesner RP. 2002. Differential contribution of NMDA receptors in hippocampal subregions to spatial working memory. Nat Neurosci 5: 162-168. doi:10.1038/nn790

Lee I, Kesner RP. 2004. Differential contributions of dorsal hippocampal subregions to memory acquisition and retrieval in contextual fear-conditioning. Hippocampus 14: 301-310. doi:10.1002/hipo.10177

Leung HT, Westbrook RF. 2008. Spontaneous recovery of extinguished fear responses deepens their extinction: a role for error-correction mechanisms. JExp Psychol Anim Behav Process 34: 461-474. doi:10.1037/ 0097-7403.34.4.461

Leung HT, Bailey GK, Laurent V, Westbrook RF. 2007. Rapid reacquisition of fear to a completely extinguished context is replaced by transient impairment with additional extinction training. J Exp Psychol Anim Behav Process 33: 299-313. doi:10.1037/0097-7403.33.3.299

Li G, Zan H, Xu Z, Casali P. 2013. Epigenetics of the antibody response. Trends Immunol 34: 460-470. doi:10.1016/j.it.2013.03.006

Maddox SA, Watts CS, Schafe GE. 2013. p300/CBP histone acetyltransferase activity is required for newly acquired and reactivated fear memories in the lateral amygdala. Learn Mem 20: 109-119. doi:10.1101/lm.029157 .112

Maren S, Quirk GJ. 2004. Neuronal signalling of fear memory. Nat Rev Neurosci 5: 844-852. doi:10.1038/nrn1535

Maren S, Aharonov G, Fanselow MS. 1996. Retrograde abolition of conditional fear after excitotoxic lesions in the basolateral amygdala of rats: absence of a temporal gradient. Behav Neurosci 110: 718-726. doi:10.1037/0735-7044.110.4.718

Melia KR, Ryabinin AE, Schroeder R, Bloom FE, Wilson MC. 1994. Induction and habituation of immediate early gene expression in rat brain by acute and repeated restraint stress. J Neurosci 14: 5929-5938. doi:10.1523/ jneurosci.14-10-05929.1994

Moita MAP, Rosis S, Zhou Y, LeDoux JE, Blair HT. 2004. Putting fear in its place: remapping of hippocampal place cells during fear conditioning. $J$ Neurosci 24: 7015-7023. doi:10.1523/JNEUROSCI.5492-03.2004

Monsey MS, Ota KT, Akingbade IF, Hong ES, Schafe GE. 2011. Epigenetic alterations are critical for fear memory consolidation and synaptic plasticity in the lateral amygdala. PLoS One 6: e19958. doi:10.1371/ journal.pone.0019958

Motanis H, Maroun M. 2012. Differential involvement of protein synthesis and actin rearrangement in the reacquisition of contextual fear conditioning. Hippocampus 22: 494-500. doi:10.1002/hipo.20915

Mowrer RR. 1987. Latent inhibition of contextual stimuli reduces the US preexposure effect in rats. Psychol Rec 37: 239-246. doi:10.1007/ BF03394986

Napier RM, Macrae M, Kehoe EJ. 1992. Rapid reaquisition in conditioning of the rabbit's nictitating membrane response. J Exp Psychol Anim Behav Process 18: 182-192. doi:10.1037/0097-7403.18.2.182

Ouyang M, Thomas SA. 2005. A requirement for memory retrieval during and after long-term extinction learning. Proc Natl Acad Sci 102: 93479352. doi:10.1073/pnas.0502315102

Paunovic N, Öst L-G. 2001. Cognitive-behavior therapy vs exposure therapy in the treatment of PTSD in refugees. Behav Res Ther 39: 1183-1197. doi:10.1016/S0005-7967(00)00093-0

Pavlov PI. 1927. Conditioned reflexes: an investigation of the physiological activity of the cerebral cortex. Oxford University Press, London.

Perry CJ, McNally GP. 2012. Naloxone prevents the rapid reacquisition but not acquisition of alcohol seeking. Behav Neurosci 126: 599-604. doi:10 $.1037 / \mathrm{a} 0029079$

Phillips RG, LeDoux JE. 1992. Differential contribution of amygdala and hippocampus to cued and contextual fear conditioning. Behav Neurosci 106: $274-285$. doi:10.1037/0735-7044.106.2.274

Pizzimenti CL, Lattal KM. 2015. Epigenetics and memory: causes, consequences and treatments for post-traumatic stress disorder and addiction. Genes Brain Behav 14: 73-84. doi:10.1111/gbb.12187 
Quirk GJ, Russo GK, Barron JL, Lebron K. 2000. The role of ventromedial prefrontal cortex in the recovery of extinguished fear. J Neurosci 20: 6225-6231. doi:10.1523/JNEUROSCI.20-16-06225.2000

Radulovic J, Kammermeier J, Spiess J. 1998. Relationship between fos production and classical fear conditioning: effects of novelty, latent inhibition, and unconditioned stimulus preexposure. J Neurosci 15: 7452-7461. doi:10.1523/JNEUROSCI.18-18-07452.1998

Rau V, Fanselow MS. 2009. Exposure to a stressor produces a long lasting enhancement of fear learning in rats. Stress 12: 125-133. doi:10.1080/ 10253890802137320

Rau V, DeCola JP, Fanselow MS. 2005. Stress-induced enhancement of fear learning: an animal model of posttraumatic stress disorder. Neurosci Biobehav Rev 29: 1207-1223. doi:10.1016/j.neubiorev.2005.04.010

Raybuck JD, McCleery EJ, Cunningham CL, Wood MA, Lattal KM. 2013. The histone deacetylase inhibitor sodium butyrate modulates acquisition and extinction of cocaine-induced conditioned place preference. Pharmacol Biochem Behav 106: 109-116. doi:10.1016/j.pbb.2013.02.009

Rescorla RA. 2000. Extinction can be enhanced by a concurrent excitor. JExp Psychol Anim Behav Process 26: 251-260. doi:10.1037/0097-7403.26.3 251

Rescorla RA. 2001. Retraining of extinguished Pavlovian stimuli. J Exp Psychol Anim Behav Process 27: 115-124. doi:10.1037/0097-7403.27.2 .115

Rescorla RA. 2004. Spontaneous recovery. Learn Mem 11: 501-509. doi:10 $.1101 / \mathrm{lm} .77504$

Rescorla RA, Heth CD. 1975. Reinstatement of fear to an extinguished conditioned stimulus. J Exp Psychol Anim Behav Process 1: 88-96. doi:10 $.1037 / 0097-7403.1 .1 .88$

Ricker ST, Bouton ME. 1996. Reacquisition following extinction in appetitive conditioning. Anim Learn Behav 24: 423-436. doi:10.3758/ BF03199014

Robbins SJ. 1990. Mechanisms underlying spontaneous recovery in autoshaping. J Exp Psychol Anim Behav Process 16: 235-249. doi:10.1037/ 0097-7403.16.3.235

Rudy JW, O'Reilly RC. 1999. Contextual fear conditioning, conjunctive representations, pattern completion, and the hippocampus. Behav Neurosci 113: 867-880. doi:10.1037/0735-7044.113.5.867

Schulz D, Canbeyli R. 1999. Freezing behavior in BNST-lesioned Wistar rats. Ann N Y Acad Sci 877: 728-731. doi:10.1111/j.1749-6632.1999.tb09311 . $\mathrm{x}$

Sierra-Mercado DS, Corcoran KA, Milad KL, Quirk GJ. 2006. Inactivation of the ventromedial prefrontal cortex reduces expression of conditioned fear and impairs subsequent recall of extinction. Eur J Neurosci 24: 17511758. doi:10.1111/j.1460-9568.2006.05014.x

Sink KS, Chung A, Ressler KJ, Davis M, Walker DL. 2013. Anxiogenic effects of CGRP within the BNST may be mediated by CRF acting at BNST CRFR1 receptors. Behav Brain Res 243: 286-293. doi:10.1016/j.bbr.2013 .01 .024

Stafford JM, Lattal KM. 2009. Direct comparisons of the size and persistence of anisomycin-induced consolidation and reconsolidation deficits. Learn Mem 16: 494-503. doi:10.1101/lm.1452209

Stafford JM, Raybuck JD, Ryabinin AE, Lattal KM. 2012. Increasing histone acetylation in the hippocampus-infralimbic network enhances fear extinction. Biol Psychiatry 72: 25-33. doi:10.1016/j.biopsych.2011.12 .012

Stafford JM, Maughan DK, Ilioi EC, Lattal KM. 2013. Exposure to a fearful context during periods of memory plasticity impairs extinction via hyperactivation of frontal-amygdalar circuits. Learn Mem 20: 156-163. doi:10.1101/lm.029801.112

Sullivan GM, Apergis J, Bush DEA, Johnson LR, Hou M, LeDoux JE. 2004. Lesions in the bed nucleus of the stria terminalis disrupt corticosterone and freezing responses elicited by a contextual but not by a specific cue-conditioned fear stimulus. Neuroscience 128: 7-14. doi:10.1016/i .neuroscience.2004.06.015

Teyler TJ, Rudy JW. 2007. The hippocampal indexing theory and episodic memory: updating the index. Hippocampus 17: 1158-1169. doi:10 $.1002 /$ hipo. 20350
Tipps ME, Raybuck JD, Buck KJ, Lattal KM. 2014. Delay and trace fear conditioning in C57BL/ 6 and DBA/2 mice: issues of measurement and performance. Learn Mem 21: 380-393. doi:10.1101/lm.035261.114

Trask S, Bouton ME. 2016. Discriminative properties of the reinforcer can be used to attenuate the renewal of extinguished operant behavior. Learn Behav 44: 151-161. doi:10.3758/s13420-015-0195-9

Treves A, Rolls ET. 1994. Computational analysis of the role of the hippocampus in memory. Hippocampus 4: 374-391. doi:10.1002/hipo .450040319

Trouche S, Bontempi B, Roullet P, Rampon C. 2009. Recruitment of adult-generated neurons into functional hippocampal networks contributes to updating and strengthening of spatial memory. Proc Natl Acad Sci 106: 5919-5924. doi:10.1073/pnas.0811054106

Waddell J, Morris RW, Bouton ME. 2006. Effects of bed nucleus of the stria terminalis lesions on conditioned anxiety: aversive conditioning with long-duration conditional stimuli and reinstatement of extinguished fear. Behav Neurosci 120: 324-336. doi:10.1037/0735-7044.120.2.324

Wagner AR. 1970. Stimulus selection and a "Modified Continuity Theory", Vol. 3, pp. 1-41. Elsevier, Amsterdam.

Walker DL, Davis M. 1997. Double dissociation between the involvement of the bed nucleus of the stria terminalis and the central nucleus of the amygdala in startle increases produced by conditioned versus unconditioned fear. J Neurosci 17: 9375-9383. doi:10.1523/JNEUROSCI 17-23-09375.1997

Walker DL, Toufexis DJ, Davis M. 2003. Role of the bed nucleus of the stria terminalis versus the amygdala in fear, stress, and anxiety. Eur J Pharmacol 463: 199-216. doi:10.1016/S0014-2999(03)01282-2

Watanabe Y, Stone E, McEwen BS. 1994. Induction and habituation of c-fos and zif/268 by acute and repeated stressors. Neuroreport 5: 1321-1324. doi:10.1097/00001756-199406270-00006

Weitemier AZ, Ryabinin AE. 2004. Subregion-specific differences in hippocampal activity between Delay and Trace fear conditioning: an immunohistochemical analysis. Brain Res 995: 55-65. doi:10.1016/j .brainres.2003.09.054

Willcocks AL, McNally GP. 2011. The role of context in re-acquisition of extinguished alcoholic beer-seeking. Behav Neurosci 125: 541-550. doi:10.1037/a0024100

Willcocks AL, McNally GP. 2013. The role of medial prefrontal cortex in extinction and reinstatement of alcohol-seeking in rats. Eur J Neurosci 37: 259-268. doi:10.1111/ejn.12031

Willcocks AL, McNally GP. 2014. An extinction retrieval cue attenuates renewal but not reacquisition of alcohol seeking. Behav Neurosci 128: 83-91. doi:10.1037/a0035595

Williams AR, Lattal KM. 2019. Rapid reacquisition of contextual fear following extinction in mice: effects of amount of extinction, acute ethanol withdrawal, and ethanol intoxication. Psychopharmacology (Berl) 236: 491-506. doi:10.1007/s00213-018-5057-7

Winocur G, Moscovitch M, Caruana DA, Binns MA. 2005. Retrograde amnesia in rats with lesions to the hippocampus on a test of spatial memory. Neuropsychologia 43: 1580-1590. doi:10.1016/j .neuropsychologia.2005.01.013

Zheng X, Deschaux O, Lavigne J, Nachon O, Cleren C, Moreau J-L, Garcia R. 2013. Prefrontal high-frequency stimulation prevents sub-conditioning procedure-provoked, but not acute stress-provoked, reemergence of extinguished fear. Neurobiol Learn Mem 101: 33-38. doi:10.1016/j.nlm .2013 .01 .003

Zimmerman JM, Maren S. 2010. NMDA receptor antagonism in the basolateral but not central amygdala blocks the extinction of Pavlovian fear conditioning in rats. Eur J Neurosci 31: 1664-1670. doi:10.1111/j $.1460-9568.2010 .07223 . x$

Zimmerman JM, Maren S. 2011. The bed nucleus of the stria terminalis is required for the expression of contextual but not auditory freezing in rats with basolateral amygdala lesions. Neurobiol Learn Mem 95: 199205. doi:10.1016/j.nlm.2010.11.002

Received February 26, 2019; accepted in revised form July 12, 2019. 


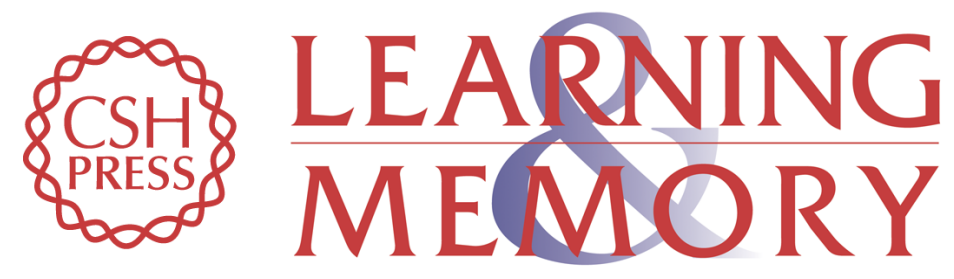

\section{Behavioral and immunohistochemical characterization of rapid reconditioning following extinction of contextual fear}

Amy R. Williams, Earnest S. Kim and K. Matthew Lattal

Learn. Mem. 2019, 26:

Access the most recent version at doi:10.1101/Im.048439.118

\begin{aligned} & \hline References $\begin{array}{l}\text { This article cites } 109 \text { articles, } 30 \text { of which can be accessed free at: } \\ \text { http://learnmem.cshlp.org/content/26/10/387.full.html\#ref-list-1 }\end{array} \\ & \begin{array}{r}\text { Creative } \\ \text { Commons } \\ \text { License }\end{array} \begin{array}{l}\text { This article is distributed exclusively by Cold Spring Harbor Laboratory Press for the } \\ \text { first } 12 \text { months after the full-issue publication date (see } \\ \text { http://learnmem.cshlp.org/site/misc/terms.xhtml). After } 12 \text { months, it is available under } \\ \text { a Creative Commons License (Attribution-NonCommercial } 4.0 \text { International), as } \\ \text { described at http://creativecommons.org/licenses/by-nc/4.0/. }\end{array} \\ & \begin{array}{c}\text { Receive free email alerts when new articles cite this article - sign up in the box at the } \\ \text { top right corner of the article or click here. }\end{array} \\ &$ Service \end{aligned} 